\title{
Percent plans, automatic admissions, and college outcomes
}

\author{
Lindsay Daugherty ${ }^{1}$, Paco Martorell ${ }^{2}$ and Isaac McFarlin $\mathrm{Jr}^{3^{*}}$
}

\author{
* Correspondence: \\ imcfar@umich.edu \\ ${ }^{3}$ Gerald R. Ford School of Public \\ Policy University of Michigan, 735 S. \\ State Street, Ann Arbor, Ml 48109, \\ USA \\ Full list of author information is \\ available at the end of the article
}

\begin{abstract}
Access to selective universities is highly coveted because of the perception that attending one provides opportunities otherwise difficult to obtain. To broaden access to the state's flagship universities in a manner that does not rely on conventional affirmative action, Texas passed the Top Ten Percent Plan in 1997, which guarantees automatic admission to any public university in the state to students in the top decile of their high school class. We estimate the effect of eligibility for automatic admissions on college choice and persistence for students in a diverse urban school district. Regression discontinuity estimates show that eligibility for guaranteed admissions has a substantial impact on enrollments at Texas flagship universities and increases the number of semesters enrolled at flagships. The increase in flagship enrollments appears to displace enrollments in private universities but has no effect on overall college enrollment or the quality of college attended. The effects are concentrated in schools that have high college-sending rates (relative to other schools in the district), suggesting that automatic admissions may have little effect on students in the most disadvantaged schools.
\end{abstract}

JEL: 12

\section{Introduction}

An influential body of research shows that the college wage premium has risen in recent decades (Katz and Murphy, 1992; Juhn et al. 1993; Goldin and Katz, 2008). Recent studies have also found that the return to attending higher-resource, selective colleges may be larger than the return to attending less-selective institutions (Andrews et al. 2012; Hoekstra, 2009; Zimmerman, 2014). This differential return to selective college attendance may be especially large for lower-income black and Hispanic students (Dale and Krueger, 2002; 2011). Despite the relatively large returns to selective college attendance among disadvantaged and underrepresented minority students, they matriculate at much lower rates than do higher-income and white students (Bastedo and Jaquette, 2011; Carnevale and Rose, 2004; Reardon et al. 2012). ${ }^{1}$ Thus, devising programs to close these gaps has considerable significance for economic policy.

"Percent plans" represent an important type of policy aimed at enhancing diversity at selective public universities. ${ }^{2}$ Currently three states, Florida, California, and Texas, have percent plans. These plans arose as a response to legal and political pressure against race-conscious affirmative action and give preferential treatment in the college admissions process to students in the top $x$ percent of their high school class (Marin

\section{党 Springer}

(C) 2014 Daugherty et al.; licensee Springer. This is an Open Access article distributed under the terms of the Creative Commons Attribution License (http://creativecommons.org/licenses/by/4.0), which permits unrestricted use, distribution, and reproduction in any medium, provided the original work is properly credited. 
and Lee, 2003; Holzer and Neumark, 2000). To the extent that there exists racial and economic stratification across high schools, percent plans could help provide students from underrepresented groups greater access to selective colleges since the admissions preference is given to the same proportion of students at every high school (Horn and Flores, 2003). However, percent plans are very controversial, with some critics claiming that they are inadequate for ensuring diversity and others arguing that they unfairly disadvantage students from more competitive high schools (Barr, 2005). ${ }^{3}$ Despite this controversy, it remains unclear how eligibility for these admissions preferences affects college outcomes. This partly reflects the fact that eligibility for automatic admission is not randomly assigned and also because it is difficult to assemble a dataset containing information on high school students that contains their class rank and is linked to college outcomes.

The purpose of this paper is to evaluate the effect of eligibility for automatic college admissions. Specifically, we estimate the effect of being eligible for automatic admissions under the Texas state policy known as the Top Ten Percent (TTP) Plan. In Texas during our study period, if a student was above the $90^{\text {th }}$ percentile of their high school's class rank distribution, they qualified for automatic admission to any Texas public college or university. ${ }^{4}$ This makes it possible to use a regression discontinuity design that identifies the causal effect of eligibility for the admissions preference by comparing the outcomes of students on either side of the top ten percent class rank cutoff. To carry out this analysis, we have assembled a dataset of high school records for students from a large, diverse Texas school district that has the information necessary for calculating class rank and that is linked to information on college enrollment from the National Student Clearinghouse (NSC).

Our approach has several important strengths. First, our data are drawn from students in a large urban school district where the majority of students are black or Hispanic and that historically has sent few students to the state's leading universities. Thus this study sheds light on whether eligibility for automatic college admissions affects college outcomes for a demographic that the TTP Plan was designed to benefit. Second, the use of college enrollment data from the National Student Clearinghouse allows us to consider a wide set of college outcomes. In particular, we can assess what types of institutions are displaced when flagship enrollment increases as a result of being in the TTP. This is also the first study on the effect of eligibility for automatic admissions examining longer-run college persistence measures.

Our findings show that eligibility for automatic admissions under the TTP Plan increases the likelihood that students in our sample enroll at a Texas flagship university. The magnitude of this effect is large; the smallest point estimates imply an increase of at least 60 percent above the baseline enrollment rate for students who barely miss being in the top decile. We also find some evidence that barely being in the top ten percent of one's class increases the total number of semesters enrolled at a flagship university over the four years following high school graduation (although by less than would be implied if the enrollment effect in the fall following high school graduation persisted over the following four years). Our results also suggest that this effect on flagship enrollment leads to substitution away from private or out-of-state colleges rather than from lower-ranked public institutions. ${ }^{5}$ In fact, we do not find that eligibility for automatic admissions affects the "quality" of colleges students attend, as measured by Barron's rankings and the 
fraction of applicants who are admitted. We also do not find evidence of an effect on the likelihood of attending college or on enrollment at a four-year college.

We find some evidence that these effects vary across student subgroups. We find statistically significant effects on measures of college choice for underrepresented minorities that are similar in magnitude to those for white and Asian students (the estimates for whites and Asians, however, are not precisely estimated). However, these effects are concentrated in schools that have high college-sending rates (relative to other schools in the district). In high schools that send relatively few students to college, we find little evidence that the automatic admissions guarantee affects any of the college outcomes we examine. Overall, our results suggest that in the urban school district we examine, offering students eligibility for automatic admissions may do little to improve access to selective colleges, especially among students who attend the most disadvantaged high schools.

\section{Background}

\subsection{Rationale for percent plans}

Selective colleges admit students on the basis of academic achievement, ACT and SAT scores, and extracurricular activities. Consequently, students who attend low-quality schools, are financially constrained, and have limited information about how the admissions process works or about financial aid opportunities are at serious disadvantage with respect to enrolling in selective colleges (Winston and Hill, 2005; Owings et al., 1995; Pallais and Turner, 2006). In particular, the lack of diversity at selective colleges and flagship universities has been attributed to the underrepresentation of low-income and black and Hispanic students (Pallais and Turner, 2006; Bowen and Bok, 1998).

One of the primary ways universities have attempted to increase the diversity of their student body is through "affirmative action" policies that grant preferences in admissions decisions to members of racial and ethnic minorities (Holzer and Neumark, 2000). However, political and legal pressure has led to rollbacks or bans in affirmative action, and as shown in Hinrichs (2010), these bans led to reductions in minority enrollment in selective colleges. ${ }^{6}$ Percent plans, including the Texas TTP Plan arose as an attempt to formulate a policy that would help maintain diversity in competitive public universities in a way that did not explicitly give admissions preferences based on race (U.S. Department of Education 2003). The idea behind these plans is that the top students in schools with high concentrations of low-income and underrepresented minority students would be eligible for admissions preferences even if their other credentials (e.g., SAT scores) were lower than those of students in more competitive high schools who did not qualify for the admissions preference. Thus, the extent to which percent plans would increase diversity in selective public universities depends on there being considerable segregation across high schools by race and socioeconomic status (Horn and Flores, 2003).

\subsection{Prior research and contributions of this study}

Much of the research on the TTP centers on how it compares to race-based affirmative action in creating diverse college campuses. Long (2004a, b) argues that there are too few minority students who would qualify for automatic admissions for the policy to offset the reductions in minority enrollment that result from banning affirmative action. 
Tienda et al. (2008) find that the perceived increases in diversity at the University of Texas - Austin under the TTP Plan are largely driven by an increase in the enrollment rates of Asian students, while enrollment rates of blacks and Hispanics declined.

There are a number of explanations for why the TTP Plan may have smaller effects than affirmative action on the enrollment of black and Hispanic students. Niu et al. (2006a) find that black and Hispanic students are less likely to be ranked in the TTP, particularly in schools with high minority populations. Even among students in the top decile, minorities and graduates from schools serving a large share of low-income students are less likely to choose selective institutions as their most preferred school Niu et al. (2006b). In addition, there are students who may be uninformed of the policy. In a recent survey of Texas seniors, Hispanic students were significantly less likely to report that they know "a lot" about the TTP Plan, a pattern that holds even among TTP students with a preference to attend a four-year university (Niu et al., 2006a). Financial constraints are also likely to play a role, though there are no studies to date that look at the potential that unmet financial need is deterring TTP students from enrolling at the Texas flagships ${ }^{7}$.

While a number of studies have examined the effects of the TTP Plan on overall enrollment rates, solid empirical evidence on how automatic admissions affect individual enrollment decisions remains limited. This is likely due to the lack of student-level data with the necessary class rank information needed to conduct such an analysis. One exception is a study by Niu and Tienda (2010) that uses survey data on a sample of high school graduates that includes administrative data on class rank at graduation. Overall, they do not find statistically significant estimates of effects on flagship enrollment, although they do find positive effects for Hispanics and those attending "typical" high schools. Fletcher and Mayer (2013) find some evidence of an increase in applications and enrollment resulting from being in the TTP. However, their sample is restricted to high school students that apply to Texas flagships, making their findings difficult to interpret.

Our paper builds on prior research in several ways. Most importantly, since our data cover a broad range of public and private institutions both inside and outside of Texas, we can examine what types of institutions are displaced by increased flagship enrollment. We can also examine whether there are effects on longer-run measures of college persistence. Second, we have information on all high school graduates from the study district, not just applicants or matriculants. This allows us to quantify the effect of eligibility for automatic admission on college outcomes and to do so for key student subgroups (e.g., college-sending rate of the student's high school). Finally, while our data are not representative of the entire state of Texas, we have large samples for a key population of interest - students in a large, diverse urban school district with traditionally low college enrollment and a large number of low-income and minority students.

\section{Institutional details}

The Texas Top Ten Percent Plan was instituted in 1997 in response to Hopwood v. Texas, a case that banned the use affirmative action in college application decisions. Rather than using explicit race-based considerations in application decisions, the TTP Plan states that students who are ranked in the top ten percent of their class must be granted automatic admission to the public Texas college of their choice. The state 
grants flexibility to districts in how they choose to calculate GPA and class rank. However, to receive automatic admission, students must provide a transcript along with their application that verifies their class rank falls within the TTP. Students must also take either the SAT or the ACT, although for students in the TTP of their high school class, these tests are not used for admissions decisions.

For students who are not in the TTP of their high school class, admissions decisions are based on standard criteria including GPA and class rank, admissions test scores, and non-academic factors such as socioeconomic status, personal statements, and extracurricular activities. ${ }^{8}$ Following the Grutter v. Bollinger decision in 2003, the University of Texas at Austin (but not Texas A\&M) reinstated race-conscious affirmative action. The aggressiveness of the new affirmative action policy, however, is unclear. There is evidence indicating that the Texas flagships did provide racial minorities preferential treatment in admissions decisions prior to the Hopwood decision and that this ended after the ban on affirmative action went into place (Long and Tienda, 2008). However, we are unaware of any research that examines the extent to which racial preferences are used in the post-Grutter context. Nonetheless, since the University of Texas at Austin uses affirmative action, in subgroup analyses we report estimates by race.

A key consideration for our study is how class rank is defined for the purposes of determining eligibility for automatic admissions. The way in which class rank is calculated could vary across schools as state law does not specify how this is to be done. Moreover, both absolute class rank and the number of students used to determine percentile class rank are not constant over time. The relevant class rank for determining eligibility for automatic admissions is the one used at the time of application to college, which might vary across students.

To better understand the process by which the relevant class rank for determining automatic admissions was calculated, we contacted counselors at each of the high schools in the district we examine as well as a representative from the district's central office. Under the student information system used in the district during our study period, class ranks were calculated centrally. Both class rank and the total number of students enrolled were calculated at the end of each semester and given to the student records office, which then distributed transcripts to high school campuses. ${ }^{9}$ However, this information is not stored by the district as part of its regular data system, and we instead calculate class rank based on course-level grade records (see Section 5 below for details).

A related issue is that both absolute class rank and the number of students used to determine percentile class rank are not constant over time. The relevant class rank for determining eligibility for automatic admissions is the one used at the time of application to college, which might vary across students. Although students can choose when to apply to college, the applications to the University of Texas system are due December $1^{\text {st }}$, and applications to TAMU are due in the middle of January. At the same time, first semester high school grades are not released in the district until late January or early February. With senior grades not available in time for application to flagship colleges, most students will be accepted to colleges under the TTP Plan according to GPA and class rank measured at the end of $11^{\text {th }}$ grade. We confirmed with high school counselors in the district that $11^{\text {th }}$ grade class rank was most likely to be reported on applications to four-year universities, especially for the flagships which have relatively early application deadlines. 


\section{How eligibility for automatic admissions can affect student outcomes}

In the college enrollment process, three distinct decisions take place: students determine which colleges they will apply to, colleges determine which students they will accept among the pool of applicants, and students must determine which college to enroll in (if any) among colleges that accept them. Automatic admissions policies could potentially affect enrollment and college choice through any of these processes (Card and Krueger, 2005).

If all students at the TTP cutoff would likely be admitted even without the TTP Plan, and if acceptance rates for students just outside of the TTP are also high, then automatic admissions might have minimal effects on student outcomes. In fact, some research suggests that this may have been the case prior to the adoption of the TTP Plan (Walker and Lavergne, 2001). However, this reasoning fails to account for the increase in applications to the flagship universities since the TTP Plan went into effect. Today, the percentage of acceptances to UT and TAMU accounted for by TTP students increased from 36 percent to 61 percent, and the recent efforts of UT to cap the percentage of enrollees who are accepted under the TTP Plan provides further evidence that Texas flagships would be unlikely to accept all top decile applicants in the absence of the policy. Moreover, some research shows that the TTP Plan expanded the set of high schools that have students that apply to the flagship universities (Long et al. 2010). If students from these schools have lower college entrance exam scores (and other credentials) than did the typical pre-TTP Plan applicant, the admissions patterns from the period before the adoption of the TTP Plan might not reflect the importance of automatic admissions to current applicants. This is especially important for our study district, which has much lower college-sending rates than is typical in Texas.

Eligibility for automatic admissions could also increase the likelihood of applying to a particular school. A number of studies find that as race-based affirmative action policies were eliminated, the decrease in probability of acceptance for minority students led to lower application rates to competitive colleges (Long, 2004b; Brown and Hirschman, 2006), even though highly qualified minority applicants were less affected (Antonovics and Backes, 2013). By increasing the probability of acceptance to 100 percent for students who are ranked in the top of their class, automatic admission policies should increase the number of applications from TTP students. Even if being in the TTP does not actually increase the probability of acceptance conditional on applying, the TTP Plan makes the admissions guarantee explicit, and this alone could change application behavior if students were not aware that they had a very high probability of being accepted without the highly visible TTP Plan.

In addition to considering the ways in which automatic admission could affect enrollment and college choice, it is also important to think of how these effects could vary across student subgroups. One of the primary purposes of the TTP Plan was to ensure diversity at college campuses, particularly in Texas flagships where black and Hispanic students have historically been underrepresented and that accept students from a relatively small number of high schools throughout Texas (Barr, 2005). Ex ante, though, it is not clear whether effects of automatic admissions would be larger or smaller for students from more disadvantaged backgrounds. On one hand, minority students in the district tend to be concentrated in the high schools that have lower college-sending rates and lower academic achievement in general. Since these students may have difficulty being 
admitted without automatic admissions, effects on outcomes like flagship enrollment might be larger for them. On the other hand, factors such as credit constraints and lack of information could mitigate the effects of automatic admission for minority students and students from schools with lower college-sending rates. These considerations motivate our analysis of the effects by race and also by whether a student attends a high school that traditionally sends few students to college.

\section{Data and descriptive statistics}

\subsection{Data}

This paper uses data from a large urban school district in Texas. We focus on graduates from the 2002 through 2008 graduating cohorts. Data files include administrative data on student demographics and high school membership, semester course files with grades, high school exit exam scores, and graduation information. Full student-level data are available beginning in 1999, allowing us to follow all students in our sample throughout high school. District files are supplemented with college data from the National Student Clearinghouse (NSC), a non-profit organization that is now the nation's leading source for postsecondary degree and enrollment verification. District student records are matched to NSC data via students' social security numbers.

Our data do not include a class rank measure, and we construct it from the district student-level data. As noted above, during our study period the class rank included on a student's transcript is calculated centrally by the district, and we follow the procedure used by the district to determine the absolute and percentile rank. First, we compute cumulative GPA at a given time using grades received in courses taken up to that point. These data come from course enrollment files that include course numbers and titles for each course in which a student is enrolled, the grade earned, and course entry and withdrawal dates (where applicable). ${ }^{10}$ Second, students are ranked within a school on the basis of cumulative GPA to determine absolute class rank at a particular time. Finally, the percentile class rank is calculated as the ratio of absolute class rank to the number of students in a school with a valid cumulative GPA. As described above, the class rank relevant for automatic admissions to UT-Austin and Texas A\&M is the rank at the end of $11^{\text {th }}$ grade. Therefore, we use this measure in our analysis.

NSC data includes semester-level observations for each NSC-reporting institution that a student attends, including date of enrollment and completion and level of enrollment (e.g. part-time, full-time). More than 92 percent of higher education institutions in the United States report to the NSC. We construct several outcomes using the NSC data. The NSC data are supplemented with data from the Integrated Postsecondary Education Data System (IPEDS) that contains other information on the intuitions students attend. We also use information on public or private funding structure and state in which the college is located to determine whether students go to college in- or out-of-state as well as whether they attend a public or private institution.

We also use the IPEDS data to construct measures related to college "quality" and cost. The first quality measure is the Barron's ranking of how competitive admission is at a particular college. We focus on using this information to classify whether or not a school is ranked by Barron's as either a "highly" or "most" competitive institution. ${ }^{11}$ The second is the selectivity defined as the fraction of applicants who are admitted. Because these variables reflect the characteristics of applicants and students enrolled 
at a given institution, they should be thought of as indicators for how prestigious a school is rather than as a proxy for some output-based measure of effectiveness. However, the admission rate closely corresponds to what "selectivity" is commonly understood to mean, as are the Barron's rankings (Hoxby, 2001). This notion of "quality" also corresponds with what is meant in public discussions about access to "elite" universities. For cost, we use the tuition "sticker price" students face at a particular institution (for which we use the 2009 tuition as listed in IPEDS). It is important to recognize that this is a limited proxy for the actual tuition students will have to pay since many of the students in our sample come from fairly disadvantaged backgrounds and would qualify for substantial amounts of financial aid. Nonetheless, because selective institutions generally charge a higher "sticker price", tuition is useful for characterizing the type of institutions students attend. Moreover, other studies examining college choice have found that tuition influences the college students attend (Long 2004a; Jacob et al. 2013).

Using the information from NSC and IPEDS, we first look at short-run measures of college enrollment and choice. These measures are based on the schools in which students enroll in the fall following graduation. Next, we look at persistence measures including year-by-year enrollment up to four years after high school graduation, total semesters enrolled in college four years after graduation, and transferring to a more (or less) selective college.

The sample used in the analysis consists of students who graduated from a district high school between 2002 and 2008. We limit the analysis to graduates because the district only obtained college enrollment data from NSC for high school graduates. One concern with doing so is that it might impart selection bias if TTP status at the end of $11^{\text {th }}$ grade affects the probability of graduation. However as we discuss below, there is no evidence for this type of effect. We also exclude students who did not have valid GPA's at the end of $11^{\text {th }}$ grade (for instance, students who transfer into the district in $12^{\text {th }}$ grade) since our empirical strategy relies on using $11^{\text {th }}$ grade percentile class rank as the running variable in the regression discontinuity estimation. Our final sample includes 17,057 students across the 7 cohorts.

\subsection{Descriptive statistics}

Table 1 provides descriptive statistics for our analysis sample by TTP status. We also show results for students close to the TTP cutoff (i.e., above the $80^{\text {th }}$ percentile) and stratified by whether a student attended a high school that sent a relatively high fraction of its graduates to college (we define a high college-sending high school as one where at least 25 percent of the graduates enroll in college in the fall following graduation). The results indicate that TTP students are more likely to be white and female and are less likely to be economically disadvantaged. As expected, TTP students are higher performing across all measures of academic achievement. Students in the TTP are more likely to graduate with a recommended or distinguished diploma, take a college entrance exam, and have much higher exit exam scores. These patterns are found in both types of high schools, although higher college-sending schools serve students from higher socioeconomic backgrounds and have much better academic achievement.

TTP students have substantially higher college-going rates than students outside the TTP. Overall, almost 60 percent of students in the TTP attend college in the fall 
Table 1 Descriptive statistics

\begin{tabular}{|c|c|c|c|c|c|c|c|c|}
\hline & \multirow[b]{3}{*}{ All } & \multicolumn{7}{|c|}{ RD sample: class rank $+/-10$ percentage points of top $10 \%$} \\
\hline & & \multicolumn{3}{|c|}{ All high schools } & \multicolumn{2}{|c|}{$\begin{array}{l}\text { High college } \\
\text { enrollment HS }\end{array}$} & \multicolumn{2}{|c|}{$\begin{array}{l}\text { Low college } \\
\text { enrollment HS }\end{array}$} \\
\hline & & All & $\begin{array}{l}\text { Top } \\
10 \% \\
\end{array}$ & $\begin{array}{c}\text { Non-top } \\
10 \%\end{array}$ & $\begin{array}{l}\text { Top } \\
10 \% \\
\end{array}$ & $\begin{array}{c}\text { Non-top } \\
10 \%\end{array}$ & $\begin{array}{l}\text { Top } \\
10 \% \\
\end{array}$ & $\begin{array}{c}\text { Non-top } \\
10 \%\end{array}$ \\
\hline \multicolumn{9}{|l|}{ Demographics } \\
\hline Male & 0.48 & 0.35 & 0.32 & 0.38 & 0.35 & 0.39 & 0.28 & 0.36 \\
\hline White & 0.27 & 0.40 & 0.43 & 0.37 & 0.60 & 0.53 & 0.16 & 0.11 \\
\hline Black & 0.29 & 0.20 & 0.18 & 0.23 & 0.21 & 0.27 & 0.12 & 0.16 \\
\hline Hispanic & 0.41 & 0.33 & 0.30 & 0.36 & 0.09 & 0.14 & 0.65 & 0.70 \\
\hline Econ. Disadvantaged & 0.54 & 0.45 & 0.41 & 0.48 & 0.20 & 0.29 & 0.74 & 0.79 \\
\hline Limited Eng. Proficiency & 0.13 & 0.08 & 0.07 & 0.09 & 0.02 & 0.04 & 0.14 & 0.18 \\
\hline Special Education & 0.11 & 0.02 & 0.01 & 0.03 & 0.01 & 0.02 & 0.01 & 0.04 \\
\hline Nbhd HH Inc: Bottom Quartile & 0.40 & 0.30 & 0.27 & 0.32 & 0.17 & 0.24 & 0.45 & 0.45 \\
\hline Nbhd HH Inc: Second Quartile & 0.29 & 0.27 & 0.24 & 0.30 & 0.16 & 0.22 & 0.37 & 0.42 \\
\hline Nbhd HH Inc: Third Quartile & 0.20 & 0.23 & 0.25 & 0.22 & 0.31 & 0.27 & 0.15 & 0.12 \\
\hline Nbhd HH Inc: Top Quartile & 0.12 & 0.20 & 0.23 & 0.16 & 0.36 & 0.26 & 0.03 & 0.01 \\
\hline \multicolumn{9}{|l|}{ High School Record } \\
\hline 10th Grade GPA & 2.96 & 3.91 & 4.16 & 3.65 & 4.26 & 3.75 & 4.00 & 3.49 \\
\hline 11th Grade GPA & 2.95 & 3.92 & 4.18 & 3.66 & 4.28 & 3.76 & 4.01 & 3.48 \\
\hline GPA at Graduation & 2.99 & 3.92 & 4.17 & 3.66 & 4.29 & 3.78 & 3.99 & 3.47 \\
\hline Recommended Diploma & 0.67 & 0.82 & 0.76 & 0.88 & 0.67 & 0.86 & 0.90 & 0.91 \\
\hline Distinguished Diploma & 0.04 & 0.14 & 0.22 & 0.06 & 0.31 & 0.09 & 0.08 & 0.01 \\
\hline Math exit exam z-score & 0.23 & 0.83 & 1.01 & 0.65 & 1.08 & 0.80 & 0.90 & 0.43 \\
\hline Reading exit exam z-score & 0.22 & 0.67 & 0.78 & 0.57 & 0.82 & 0.66 & 0.73 & 0.41 \\
\hline Took SAT or ACT & 0.31 & 0.50 & 0.55 & 0.45 & 0.58 & 0.52 & 0.50 & 0.35 \\
\hline \multicolumn{9}{|l|}{$\begin{array}{l}\text { College Outcomes } \\
\text { (Year following Graduation) }\end{array}$} \\
\hline Enrolled in College & 0.30 & 0.51 & 0.58 & 0.44 & 0.68 & 0.56 & 0.40 & 0.26 \\
\hline Enrolled in 4 Yr. College & 0.20 & 0.45 & 0.54 & 0.36 & 0.66 & 0.48 & 0.33 & 0.16 \\
\hline Enrolled Private School & 0.05 & 0.11 & 0.13 & 0.10 & 0.14 & 0.12 & 0.11 & 0.05 \\
\hline Enrolled Out of State & 0.04 & 0.07 & 0.09 & 0.05 & 0.13 & 0.08 & 0.03 & 0.02 \\
\hline $\begin{array}{l}\text { Enrolled Most/Highly } \\
\text { Competitive }\end{array}$ & 0.08 & 0.27 & 0.37 & 0.16 & 0.47 & 0.23 & 0.21 & 0.04 \\
\hline Enrolled at UT Austin & 0.02 & 0.08 & 0.13 & 0.03 & 0.17 & 0.04 & 0.06 & 0.00 \\
\hline Enrolled at Texas A\&M & 0.02 & 0.06 & 0.08 & 0.04 & 0.11 & 0.06 & 0.04 & 0.00 \\
\hline Enrolled at a Flagship & 0.04 & 0.14 & 0.21 & 0.07 & 0.28 & 0.11 & 0.10 & 0.01 \\
\hline $\begin{array}{l}\text { Admission rate } \\
\text { (not enrolled=100\%) }\end{array}$ & 0.93 & 0.83 & 0.78 & 0.88 & 0.73 & 0.84 & 0.88 & 0.95 \\
\hline $\begin{array}{l}\text { Admission rate } \\
\text { (drop not enrolled) }\end{array}$ & 0.76 & 0.67 & 0.63 & 0.73 & 0.60 & 0.71 & 0.69 & 0.81 \\
\hline \multicolumn{9}{|l|}{$\begin{array}{l}\text { College Persistence } \\
\text { (within } 4 \text { years) }\end{array}$} \\
\hline Total Semesters at Flagship & 0.28 & 1.00 & 1.52 & 0.49 & 2.07 & 0.77 & 0.62 & 0.05 \\
\hline Total Semesters at 4yr. & 1.39 & 3.28 & 4.03 & 2.52 & 4.97 & 3.53 & 2.50 & 0.93 \\
\hline Sample Size & 17,085 & 4,196 & 2,105 & 2,091 & 1,304 & 1,281 & 801 & 810 \\
\hline
\end{tabular}


following graduation compared to only 44 percent in the next decile ( 26 percent among all students in the bottom 90 percent). These differences are especially stark for flagship university enrollment, with 21 percent of TTP students attending a flagship (or about one-in-three students who enroll in college) compared to only 7 percent for those in the $80^{\text {th }}$ to $90^{\text {th }}$ percentiles. However, sizable differences also exist for enrollment at private and out-of-state institutions, which suggests that the causal effect of being in the TTP on flagship enrollment is at most only a portion of the raw difference in flagship enrollment for TTP and non-TTP students.

Two other patterns bear mentioning. First, only 10 percent of TTP students in the lower-sending high schools enroll in a flagship, compared to almost 30 percent in the higher-sending schools. This difference motivates our examination of heterogeneity in the effects of being in the TTP between these types of high schools. Second, collegesending rates overall in the district are low. Statewide, during our study period, the percent of high school graduates enrolled in college in the fall following graduation ranged from 52 to 56 percent (THECB, 2010), but only 30 percent of graduates in this district enrolled in college. Even in the high schools that send large numbers of students to college relative to the district overall, only 37 percent of graduates enroll in college (the fraction who attend college in the top 20 percent in these schools, i.e., what is reported in columns 5 and 6 of Table 1, is much higher).

Third, the fraction of students in the top ten percent in our sample $(2,105 / 17,085=$ 0.12 ) is greater than ten percent. This is because, as described above, we use class rank at the end of $11^{\text {th }}$ grade in our analysis and to determine top ten percent status, but our sample consists of high school graduates. Since students drop out between the end of $11^{\text {th }}$ grade and graduation, and dropouts are much more likely for students with low GPA's, percentile class rank tends to worsen over this period. This has two important implications. First, more than ten percent of graduates will be eligible for automatic admissions since the end of $11^{\text {th }}$ grade GPA is the final GPA determined before applications are due to the flagship universities. Second, there are likely to be discrepancies between class rank at graduation and at $11^{\text {th }}$ grade. ${ }^{12}$ As described in the next section, measurement error in the class rank measure could bias the estimates, and this is likely to be worse when using class rank at graduation as the running variable in the RD analysis since class rank at graduation is determined after college application and admissions decisions are made. ${ }^{13}$

\section{Methods}

\subsection{Research design and estimation}

The goal of this paper is to estimate the effect of being eligible for automatic admission to the Texas public universities via membership in the top decile of one's high school class. The empirical challenge we face stems from the differences between TTP students and those with lower class rank, some of which are documented in Table 1. To credibly estimate the effect of being in the TTP, we use an approach that mimics randomly assigning placement into the TTP. Specifically, we employ a regression discontinuity research design that relies on comparisons between students whose class rank is just above or below the cutoff used for eligibility for automatic admissions. As demonstrated by Lee (2008), as long as students cannot exert complete control over their exact class rank (i.e., there is some randomness in class rank at the point 
when students apply to college), whether a student falls just above or below the TTP class rank threshold is "as good as" random, and students on either side of the threshold should be similar in all respects other than one being in the top decile and the other not.

To formalize these ideas consider the following model for some outcome, $Y_{i}$ (e.g., enrollment in a Texas flagship university):

$$
Y_{i}=\theta T T P_{i}+f\left(C_{i}\right)+X_{i} \beta+e_{i}
$$

Where $\mathrm{CR}_{\mathrm{i}}$ is the ranking of student $\mathrm{i}$ in her high school class (measured as the fraction of students with a higher GPA than student $i), T^{2} P_{i}$ is an indicator variable equal to 1 if a student is in the TTP of her class (i.e., $\left.T_{i}=1\left(\mathrm{CR}_{\mathrm{i}}<.10\right)\right)$, $\mathrm{X}_{\mathrm{i}}$ is a vector of observable covariates, and $e_{i}$ is a random disturbance term. The function $f(\cdot)$ is function of class rank that captures the relationship between the outcome and class rank away from the TTP cutoff.

The key assumption underlying our approach is that falling just above or below the ten percent cutoff is not systematically related to other factors that affect the outcomes of interest (i.e., $\mathrm{e}_{\mathrm{i}}$ ). The primary threat to the research design is that students manipulate their class rank in order to just get above the ten percent cutoff. ${ }^{14}$ While students may alter the mix of courses they take and petition for better grades in order to increase their chances of being in the top decile of their class, course performance is at least somewhat uncertain and students are unlikely to have perfect information about exactly what their classmate's GPA will be. This makes it unlikely that students can manipulate their exact class rank with the precision necessary to undermine our empirical strategy.

In addition to being credible on a priori grounds, the assumptions underlying the research design can be tested by examining baseline covariates and examining whether they "trend smoothly" through the ten percent cutoff (Lee, 2008; Imbens and Lemieux, 2008) and whether the distribution of class rank is discontinuous at the ten percent cutoff. Below we show evidence consistent with the identification assumptions we make. We also report results from specifications that include controls for baseline covariates, which should improve the precision of the estimates and have little effect on the point estimates if the controls are "balanced" on either side of the cutoff.

Obtaining consistent estimates of the discontinuity in a given outcome depends crucially on modeling $\mathrm{f}(\cdot)$ in Equation 1 appropriately. We follow the suggestion of Imbens and Lemieux (2008) and Imbens and Kalyanaraman (2009) and use local linear regression in a bandwidth around the TTP cutoff, where the slopes are allowed to differ for students below and above the $90^{\text {th }}$ percentile cutoff. ${ }^{15}$ To assess the sensitivity of bandwidth choice, we report estimates from three different specifications. The first two are OLS local linear regression models with a bandwidth of either 10 or 5 percentile ranking points. To further assess which specification is most trustworthy for a given outcome, we also present graphical evidence showing the regression fit and local means. The degree to which the regression fit "tracks" the local means near the cut point is informative about whether the estimated discontinuity is being driven by misspecification of $f(\cdot)$. If the regression fit tracks the underlying data well, then it provides reassurance that the estimated discontinuities are reliable. As a final check 
on the robustness of the results, we also use as a third specification the estimator proposed by Imbens and Kalyanaraman (2009; henceforth IK) that uses weighted local linear regression and a data-driven bandwidth choice.

\subsection{Interpretation}

Our approach is designed to produce internally valid estimates of the effect of being in the top ten percent of one's class. As noted above, any effects could be operating by changing the likelihood of applying to a particular university, the probability of acceptance conditional on application, or the probability of enrollment conditional on acceptance. We are not able to distinguish from among these mechanisms since we only observe enrollment outcomes and not application or admissions decisions. Thus, our estimates should be thought as the reduced-form effect of barely being in the TTP at a time when state law guaranteed automatic admission for students in the top decile of their high school class.

While eligibility for automatic admission to the Texas public universities is the most noteworthy consequence of being in the TTP, as described above, the policy in place in Texas during this time included outreach efforts that targeted students in the TTP, especially at schools that serve large numbers of disadvantaged students and where students are eligible to apply for Longhorn or Century scholarships. This outreach may have had independent effects on college enrollment by, for instance, increasing information about college. As such, our results should be interpreted as estimates of the combined effect of automatic admission and the accompanying outreach efforts that are part of the Texas TTP Plan ${ }^{16}$.

In addition, as with any regression discontinuity design, our estimates are "local" to the cutoff; specifically, they capture a weighted average of individual-level effects where the weights are a function of the probability of being at the ten percent cutoff (Lee, 2008). In this case, the effect near the cutoff has considerable policy relevance. This is because the controversy surrounding the TTP Plan largely stems from the perception that the law lets "under-qualified" students gain admission to the most selective universities, and our estimates shed light on the students for whom this claim is most relevant. Moreover, our results are informative about the likely consequences of a change in the automatic admissions cutoff, such as that which went into effect at UT Austin in the fall of 2011.

\section{Results}

\subsection{Tests of the identification assumptions}

As described in the preceding section, the assumptions underlying our research design can be tested by examining whether baseline covariates exhibit discontinuous changes at the ten percent cutoff. Table 2 demonstrates that discontinuity estimates for the baseline covariates are generally small in magnitude, and there are no covariates for which we found statistically significant discontinuities across all bandwidth specifications. As a summary measure of all of the covariates, we predicted the probability of 4-year college enrollment as a function of baseline covariates, which places most weight on covariates which are relevant predictors of college enrollment. As seen in Figure 1, there is no evidence that this measure jumps discontinuously at the TTP cutoff.

A second test of the identification assumption is to examine whether the distribution of class rank is continuous at the cut point (McCrary, 2008). Because we restrict the 
Table 2 Discontinuities in baseline covariates

\begin{tabular}{|c|c|c|c|}
\hline \multirow[t]{2}{*}{ E(Enroll 4Yr College |X) } & 0.001 & 0.010 & 0.015 \\
\hline & $(0.011)$ & $(0.015)$ & $(0.028)$ \\
\hline \multirow[t]{2}{*}{ Male } & -0.028 & 0.025 & 0.020 \\
\hline & $(0.030)$ & $(0.041)$ & $(0.062)$ \\
\hline \multirow[t]{2}{*}{ Economically Disadvantaged } & -0.011 & 0.020 & -0.059 \\
\hline & $(0.031)$ & $(0.043)$ & $(0.065)$ \\
\hline \multirow[t]{2}{*}{ African American } & 0.013 & 0.026 & -0.049 \\
\hline & $(0.025)$ & $(0.036)$ & $(0.067)$ \\
\hline \multirow[t]{2}{*}{ White } & 0.003 & 0.003 & 0.067 \\
\hline & $(0.030)$ & $(0.042)$ & $(0.063)$ \\
\hline \multirow[t]{2}{*}{ Other Ethnicity } & -0.007 & 0.023 & -0.061 \\
\hline & $(0.027)$ & $(0.039)$ & $(0.072)$ \\
\hline \multirow[t]{2}{*}{ Limited English Proficiency } & 0.021 & -0.007 & -0.003 \\
\hline & $(0.018)$ & $(0.025)$ & $(0.041)$ \\
\hline \multirow[t]{2}{*}{ Special Education } & 0.002 & 0.005 & -0.001 \\
\hline & $(0.008)$ & $(0.011)$ & $(0.015)$ \\
\hline \multirow[t]{2}{*}{ Reading Exit Exam Z-score } & $-0.078^{*}$ & -0.026 & -0.016 \\
\hline & $(0.038)$ & $(0.055)$ & $(0.082)$ \\
\hline \multirow[t]{2}{*}{ Math Exit Exam Z-score } & -0.038 & 0.041 & 0.032 \\
\hline & $(0.043)$ & $(0.060)$ & $(0.086)$ \\
\hline \multirow[t]{2}{*}{ Missing Math Exit Exam } & 0.019 & 0.016 & 0.024 \\
\hline & $(0.018)$ & $(0.025)$ & $(0.039)$ \\
\hline \multirow[t]{2}{*}{ Missing Reading Exit Exam } & 0.015 & -0.000 & 0.019 \\
\hline & $(0.018)$ & $(0.025)$ & $(0.039)$ \\
\hline \multirow[t]{2}{*}{ Graduation cohort } & -0.062 & -0.035 & -0.016 \\
\hline & $(0.106)$ & $(0.149)$ & $(0.188)$ \\
\hline \multirow[t]{2}{*}{ GPA middle grade 11} & $-0.047^{*}$ & -0.001 & 0.011 \\
\hline & $(0.019)$ & $(0.028)$ & $(0.044)$ \\
\hline \multirow[t]{2}{*}{ GPA end of grade 10} & -0.032 & 0.002 & 0.017 \\
\hline & $(0.020)$ & $(0.029)$ & $(0.046)$ \\
\hline \multicolumn{4}{|l|}{ HH Income Quartile of Census Blk Group } \\
\hline \multirow[t]{2}{*}{ Bottom Quartile } & 0.018 & 0.017 & -0.109 \\
\hline & $(0.029)$ & $(0.041)$ & $(0.071)$ \\
\hline \multirow[t]{2}{*}{ Second Quartile } & -0.025 & -0.019 & 0.059 \\
\hline & $(0.027)$ & $(0.038)$ & $(0.061)$ \\
\hline \multirow[t]{2}{*}{ Third Quartile } & -0.032 & -0.058 & -0.057 \\
\hline & $(0.026)$ & $(0.037)$ & $(0.059)$ \\
\hline \multirow[t]{2}{*}{ Top Quartile } & 0.042 & $0.067^{*}$ & $0.118^{*}$ \\
\hline & $(0.024)$ & $(0.033)$ & $(0.051)$ \\
\hline Bandwidth & 10 & 5 & IK opt bw \\
\hline
\end{tabular}

Note: Estimates are estimated discontinuities for a covariate at the TTP cutoff. Columns 1 and 2 use local linear regression with slopes varying on either side of TTP cutoff and with bandwidths of 10 and 5 percentage points, respectively; robust standard errors in parentheses. Column 3 uses the Imbens and Kalyanaraman procedure for point estimates and standard errors. $\mathrm{N}$ for bw $=10$ is 4,196 and for bw=5 is 2107 ( $\mathrm{N}$ varies by covariate in column 3 ). ${ }^{*}$ denote statistically significant estimate at the $1 \%$ and $5 \%$ level, respectively. 


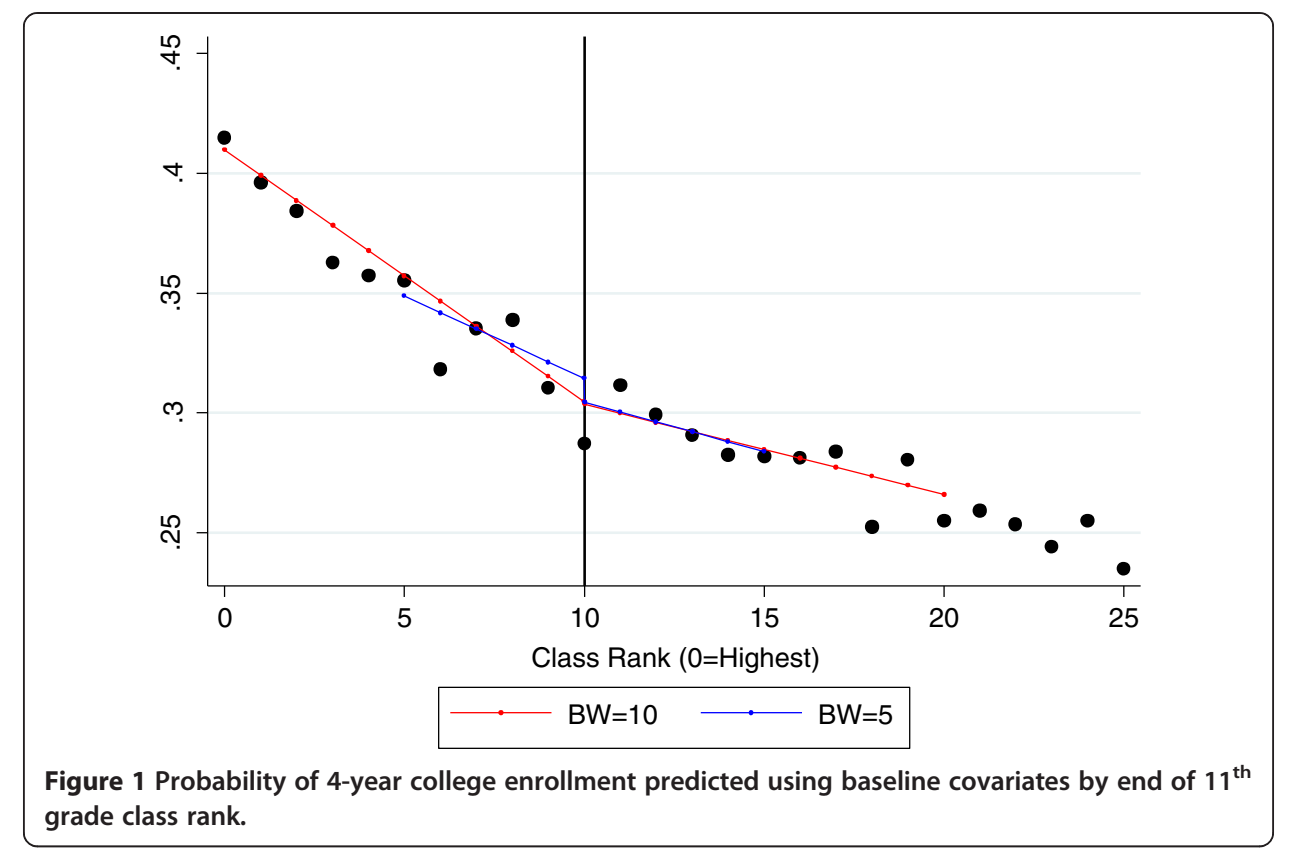

sample to high school graduates, the distribution of $11^{\text {th }}$ grade percentile class rank is not uniformly distributed. In particular, if end of $11^{\text {th }}$ grade TTP status affects the likelihood of high school graduation, then the distribution of class rank will be discontinuous at the TTP cutoff. As noted earlier, this type of sorting into the TTP at the cutoff could impart selection bias. Fortunately, the evidence in Figure 2 reveals no indication of any such manipulation, nor does the estimate from the "McCrary test" (McCrary, 2008) of a discontinuous density (the point estimate is -0.01 and the standard error is $0.06)$.

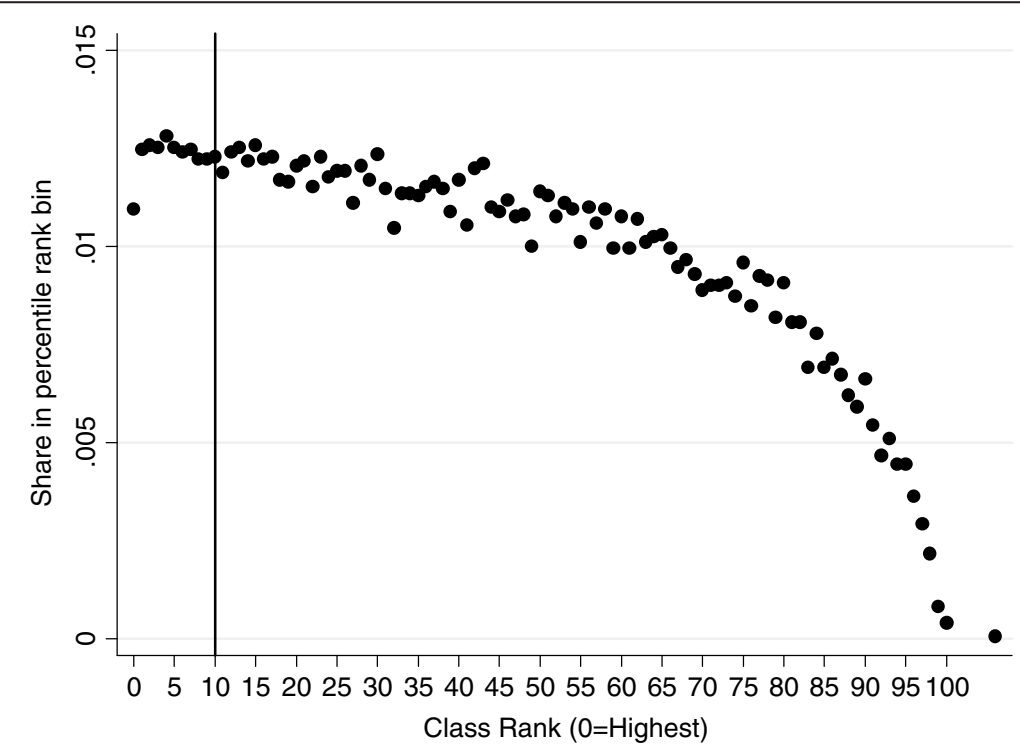

Figure 2 Distribution of class rank at end of $11^{\text {th }}$ grade, 2002-2007 high school graduates. 


\subsection{Effects on college enrollment and choice}

Table 3 presents the estimates of the effect of being in the TTP on college enrollment and college choice outcomes. As mentioned previously, all of these outcomes refer to enrollment in the fall following graduation from high school. The results indicate that membership in the TTP does increase flagship enrollment. The estimates range from about 5 to 7 percentage points in columns 1-4 (local linear regressions with bandwidths of 5 or 10 percentage points) and 11 to 14 percentage points in the IK specification, which uses a very narrow bandwidth. These results provide strong evidence that eligibility for automatic admissions increases the likelihood of flagship university attendance, although the magnitude of the effect is somewhat sensitive to the model specification. When examining effects on flagship enrollment separately for the two flagship universities, we find positive estimates for both Texas A\&M and UT-Austin, although these are not always statistically significant. Graphical evidence consistent with these results

Table 3 Effect of being in top $10 \%$ at end of 11 th grade on college enrollment and choice

\begin{tabular}{|c|c|c|c|c|c|c|}
\hline \multirow[t]{2}{*}{ Enrolled in Flagship } & $0.057^{* *}$ & $0.053^{* *}$ & $0.074^{*}$ & $0.066^{*}$ & $0.136^{* *}$ & $0.110^{* *}$ \\
\hline & $(0.021)$ & $(0.020)$ & $(0.029)$ & $(0.027)$ & $(0.048)$ & $(0.042)$ \\
\hline \multirow[t]{2}{*}{ Enrolled UT Austin } & $0.042^{* *}$ & $0.040^{* *}$ & 0.032 & 0.027 & 0.077 & 0.063 \\
\hline & $(0.016)$ & $(0.016)$ & $(0.023)$ & $(0.022)$ & $(0.041)$ & $(0.039)$ \\
\hline \multirow[t]{2}{*}{ Enrolled Texas A\&M } & 0.016 & 0.014 & $0.039^{*}$ & 0.037 & 0.058 & 0.048 \\
\hline & $(0.015)$ & $(0.014)$ & $(0.020)$ & $(0.020)$ & $(0.031)$ & $(0.030)$ \\
\hline \multirow[t]{2}{*}{ Enrolled Public Non-Flagship } & -0.016 & -0.010 & -0.017 & -0.013 & -0.097 & -0.089 \\
\hline & $(0.023)$ & $(0.023)$ & $(0.033)$ & $(0.032)$ & $(0.056)$ & $(0.049)$ \\
\hline \multirow[t]{2}{*}{ Enrolled Private or Out-of-State } & $-0.081^{* *}$ & $-0.079^{* *}$ & -0.028 & -0.030 & -0.075 & -0.076 \\
\hline & $(0.024)$ & $(0.023)$ & $(0.033)$ & $(0.031)$ & $(0.055)$ & $(0.050)$ \\
\hline \multirow[t]{2}{*}{ Enrolled Out-of-State } & -0.012 & -0.013 & 0.005 & 0.005 & 0.013 & 0.010 \\
\hline & $(0.015)$ & $(0.015)$ & $(0.021)$ & $(0.021)$ & $(0.036)$ & $(0.034)$ \\
\hline \multirow[t]{2}{*}{ Enrolled Private } & $-0.069^{* *}$ & $-0.066^{* *}$ & -0.033 & -0.035 & -0.090 & -0.085 \\
\hline & $(0.019)$ & $(0.019)$ & $(0.027)$ & $(0.026)$ & $(0.052)$ & $(0.049)$ \\
\hline \multirow[t]{2}{*}{ Enrolled 4 Year } & -0.041 & -0.036 & 0.017 & 0.010 & -0.050 & -0.064 \\
\hline & $(0.030)$ & $(0.027)$ & $(0.043)$ & $(0.038)$ & $(0.067)$ & $(0.054)$ \\
\hline \multirow[t]{2}{*}{ Enrolled any College } & -0.040 & -0.036 & 0.029 & 0.022 & -0.023 & -0.042 \\
\hline & $(0.031)$ & $(0.028)$ & $(0.044)$ & $(0.039)$ & $(0.070)$ & $(0.059)$ \\
\hline \multirow{2}{*}{$\begin{array}{l}\text { Enrolled Highly or } \\
\text { Most Competitive College }\end{array}$} & -0.009 & -0.010 & 0.055 & 0.043 & 0.065 & 0.035 \\
\hline & $(0.027)$ & $(0.024)$ & $(0.038)$ & $(0.033)$ & $(0.060)$ & $(0.049)$ \\
\hline \multirow[t]{2}{*}{ Selectivity (\% Admitted) } & 0.015 & 0.014 & -0.016 & -0.013 & -0.000 & 0.003 \\
\hline & $(0.012)$ & $(0.011)$ & $(0.017)$ & $(0.015)$ & $(0.029)$ & $(0.024)$ \\
\hline \multirow{2}{*}{$\begin{array}{l}\text { Tuition (Sticker Price), } \\
\text { zero if not enrolled }\end{array}$} & $-1751.048^{* *}$ & $-1650.040^{* *}$ & -243.655 & -329.141 & -589.470 & -632.018 \\
\hline & $(575.676)$ & $(524.495)$ & (792.473) & (720.169) & (788.656) & (692.873) \\
\hline Bandwidth & 10 & 10 & 5 & 5 & IK opt bw & IK opt bw \\
\hline Baseline covariates? & No & Yes & No & Yes & No & Yes \\
\hline
\end{tabular}

Note: Outcomes refer to enrollment and choice in the semester following high school graduation. Columns 1 and 2 use local linear regression with bandwidths of 10 and 5 percentage points, respectively; robust standard errors in parentheses. Column 3 uses the Imbens and Kalyanaraman procedure for point estimates and standard errors. $\mathrm{N}$ for bw $=10$ is 4,196 and for bw=5 is 2107 ( $\mathrm{N}$ varies by covariate in column 3 ). ${ }^{* *}$, * denote statistically significant estimate at the $1 \%$ and $5 \%$ level, respectively. 
can be seen in Figure 3, which shows local averages (in bins 1 percentile point wide) and local linear regression fits (separately for bandwidths of 5 and 10 percentage points). The results for flagship attendance (upper-left panel) clearly show that the likelihood of attending a flagship drops when class rank falls above the ten percent cutoff.

Three other points about the flagship enrollment results are noteworthy. First, the estimates are not very sensitive to the inclusion of baseline covariates, which is consistent with the baseline covariates being balanced on either side of the TTP cutoff. Second, the fact that we find a discontinuity in flagship enrollment suggests that measurement error in our class rank measure might be minimal. This is because even small amounts of error in either the GPA calculation or the count of students included in the denominator could wipe out any discontinuity that exists at the actual TTP cutoff when using the noisy class rank measure (Pei, 2011). ${ }^{17}$ Third, the effects are large in magnitude. Only about 9 percent of students who barely miss being in the TTP enroll in a flagship, so even the smallest point estimates imply being in the TTP increases the likelihood of flagship enrollment by almost 60 percent.

A key question is whether this effect on TTP enrollment reflects an overall increase in the likelihood of enrolling in college. The estimates in Table 3 offer little indication that this is the case. Across all specifications, the largest point estimate of the effect of being in the TTP on enrollment in a four-year institution is 2 percentage points. In the specification with the most precise estimates (bandwidth of 10 controlling for baseline covariates), we can rule out effects larger than about 2 percentage points. These estimates are consistent with the lack of a discontinuity in the probability of 4-year college enrollment at the TTP cutoff as seen in the lower-right panel of Figure 3. We find very similar results when examining the effect of enrolling in any college, which includes enrollment at two-year community colleges.

A positive effect on flagship enrollment but no effect on overall college enrollment implies that the increase in flagship enrollment must be displacing enrollment at some other type of institution. One possibility is that students who would go to a flagship if

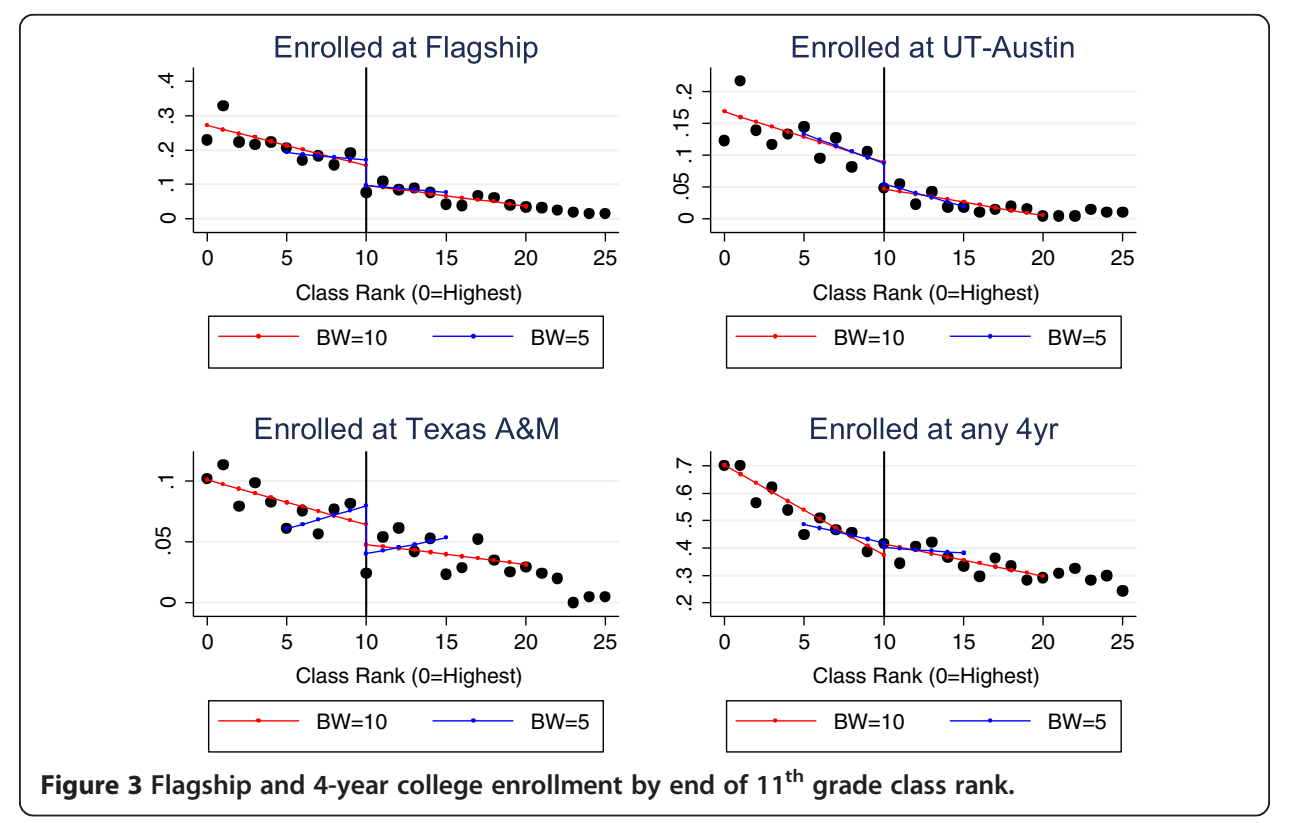


they barely make it into the TTP would go to a lower-ranked public university if they barely missed it. We find little evidence of this type of displacement, as we see no discontinuity in the probability of attending a public non-flagship institution at the TTP cutoff. The estimates in Table 3 from the models with a bandwidth of 10 and 5 are very close to zero. The estimates from the IK estimator are negative and larger in magnitude, but imprecisely estimated due to the very narrow bandwidth (1.96 percentage points). We also do not find evidence that TTP affects enrollment in any college, suggesting that it does not increase community college enrollment either, but this is to be expected since these schools admit anyone with a high school degree.

We do find some evidence that being in the TTP displaces enrollment at private or out-of-state colleges. The upper-right panel of Figure 3 shows that enrollment in these institutions trends downward with class rank but that it appears to jump up at the TTP cutoff. The estimates in Table 3 with the bandwidth of 10 and the IK specification are negative and about 7-8 percentage points as well as statistically significant with the wider bandwidth. The estimates for the bandwidth of 5 are also negative but smaller in magnitude and not statistically significant. When examining enrollment in private and out-of-state enrollment separately, the estimates in Table 3 suggest that any displacement seems to be operating through a reduction in enrollment in private institutions rather than out-of-state institutions since the estimates for out-of-state enrollment are small and not statistically significant.

Next, we examined whether TTP status affects measures of college "quality". This is important, because eligibility for automatic admissions is designed to help improve access to elite universities by guaranteeing access to the state's flagship institutions. On the other hand, much of the opposition to the TTP Plan centers on the claim that students admitted the TTP Plan's automatic admissions guarantee will take spots from better-qualified students who are not admitted under the TTP Plan because they attend more competitive high schools. To examine this issue, we first estimate the effect of eligibility for automatic admission on the probability of enrolling in a college ranked by Barron's as either a "highly" or "most" competitive institution. The point estimates in Table 3 are not statistically significant, but the magnitudes are sensitive to the choice of bandwidth. With a bandwidth of 10, the estimates are very close to zero and statistically insignificant. The estimates with narrower bandwidths are positive and larger in magnitude but are too imprecisely estimated to be statistically significant. This is consistent with the graphical evidence in the lower-left panel of Figure 4, where there is not clear evidence of a sharp change in this outcome at the TTP cutoff. Next, we use a continuous measure of selectivity defined as the fraction of applicants to a college who were admitted (so that a lower value of the measure indicates a more selective institution). ${ }^{18}$ The lower-right panel of Figure 4 shows that selectivity is strongly related to class rank but that there is no discontinuous change in average college selectivity at the TTP cutoff. Similarly, the point estimates in Table 3 are small in magnitude and statistically insignificant.

Taken together, the above results provide very little indication automatic eligibility for admission under the TTP Plan affects the "quality" of institutions students attend. However, since it appears that automatic admissions increases flagship enrollment at the expense of private university attendance, it may be that students attend more expensive colleges. To address this question, we estimated effects on annual tuition charged by 


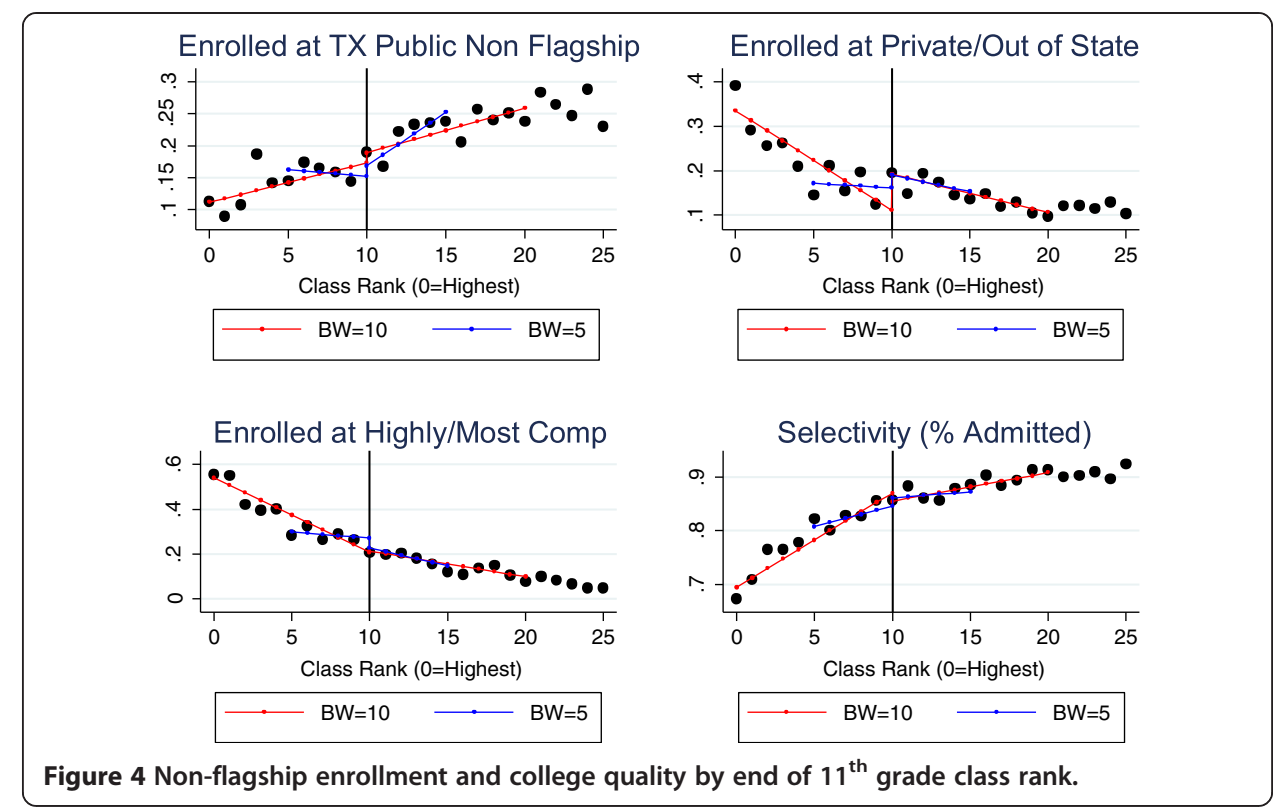

the colleges students attend. ${ }^{19}$ As noted earlier, the sticker price tuition is likely to severely overstate the actual tuition faced by many students in our sample, but it still is useful for characterizing the type of institution students attend, and also because it has been shown to be correlated with college choice (Long 2004a; Jacob et al., 2013). The estimates in Table 3 offer some evidence that barely being in the TTP leads to attending a college with lower sticker price tuition, but the estimate is only statistically significant with the bandwidth of 10. The estimates for narrower bandwidths are smaller and not statistically significant.

\subsection{Effects on college persistence}

We now turn to outcomes that characterize student persistence in college. Figure 5 shows flagship enrollment by class rank in years 2-4 following high school graduation as well as total semesters spent in a flagship 4 years after graduation. For enrollment in years 2-4, it appears flagship enrollment is higher just to the left of the TTP cutoff, although the magnitude of any discontinuity is smaller than it is for year 1 enrollment (Figure 3). This is confirmed in Table 4, where the point estimates are smaller in magnitude than they are for year 1 flagship enrollment and not statistically significant. The average of total semesters spent in a flagship does appear to change discontinuously at the TTP cutoff. The estimates in Table 4 are positive and statistically significant with the bandwidth in the IK specification (and 3 out of the 4 other estimates are also statistically significant at the 10 percent level). The magnitude of the estimates is about 4 to 5 times larger than the effect on year 1 flagship enrollment in Table 3. This is consistent with the effects of being in the TTP on flagship enrollment in subsequent years being positive but fading out relative to the effect in year 1 . In contrast if the year 1 enrollment effect were persistent throughout the following four years, the effect on total semesters at a flagship would be 8 times as large as the year 1 enrollment effect.

Figure 6 shows results for enrollment in private or out-of-state schools. For year-byyear enrollment and for total semesters, there is some indication that students in the 


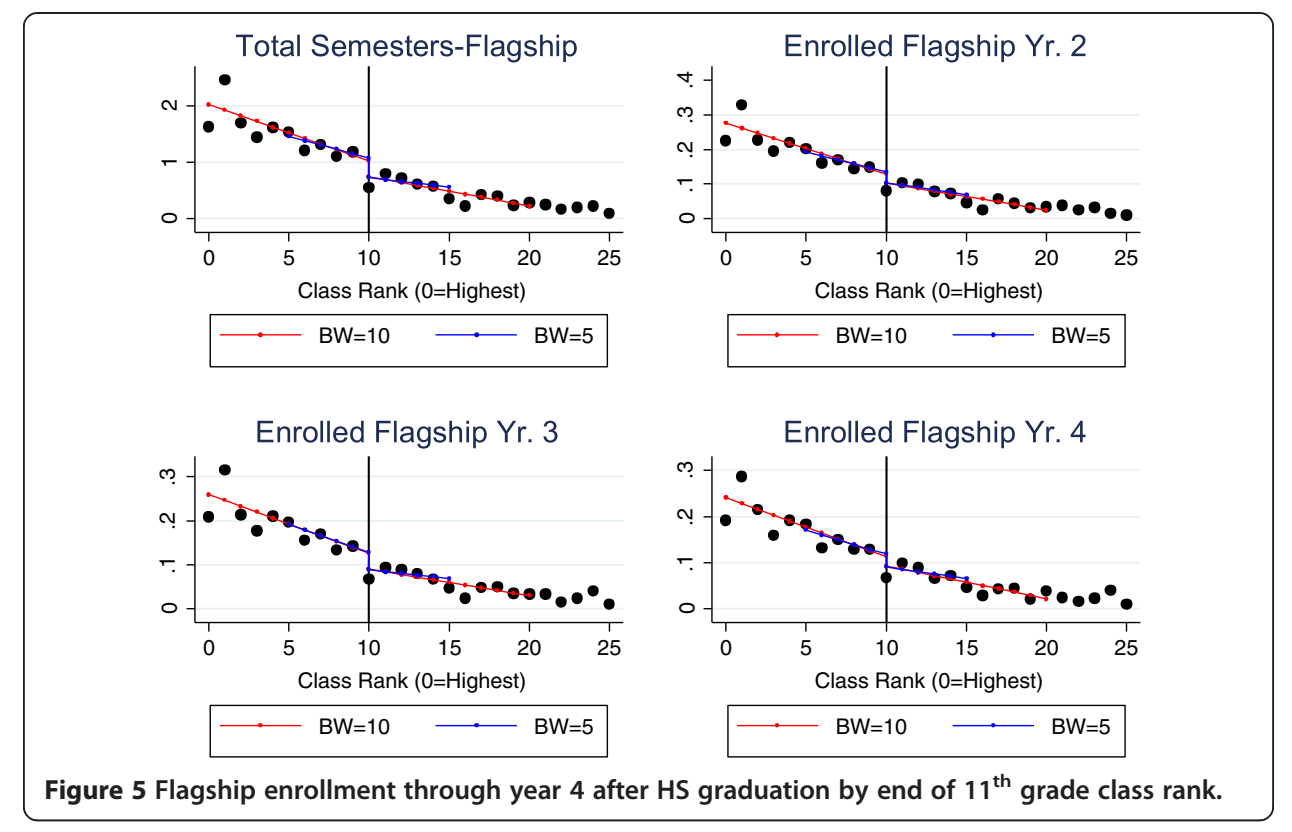

TTP are less likely to be enrolled (or enroll in fewer semesters) in private or out-ofstate colleges. The point estimates in Table 4 for a bandwidth of 10 are negative and statistically significant for year 2 enrollment and total semesters (the estimates for year 3 and 4 enrollment are at the margin for statistical significance), and the estimates for the IK specification are similar in magnitude but less precisely estimated. However, the estimates from the model with a bandwidth of 5 are smaller in magnitude and not statistically significant, although they are still negative. Overall, these results suggest that being in the TTP may lead to persistent displacement of private or out-of-state enrollment, although the estimates are somewhat sensitive to the regression specification. Figure 7 shows similar graphs for enrollment in any 4-year college. The visual evidence does not suggest that there is any effect of being in the TTP on either year-by-year enrollment nor on total semesters enrolled in college. The point estimates in Table 4 again exhibit sensitivity to the specification but are never statistically significant and are not consistently positive or negative.

Given that we find that the effect on flagship enrollment declines over time, an important question is whether this is being driven by students admitted under the TTP dropping out at a higher rate than other students. For instance, it may be that students admitted because of TTP are not able to do well in the rigorous academic environment of the flagship universities. ${ }^{20}$ To investigate this possibility, we examined whether being in the TTP affected the likelihood of transferring to a more (or less) selective institution (measured by the Barron's competitive admissions ratings) and the probability of dropping out of college. The evidence in Figure 8 provides no indication of any effects on these outcomes, which is consistent with the point estimates in Table 4.

\subsection{Subgroup analyses}

Table 5 shows estimates by subgroups. The first panel shows results stratified by race, with whites and Asians compared to underrepresented minority students (i.e., Hispanics, blacks, and Native Americans). The estimated effects on flagship enrollment are more 
Table 4 Effect of being in top $10 \%$ at end of 11 th grade on persistence outcomes

\begin{tabular}{|c|c|c|c|c|c|c|}
\hline \multirow[t]{2}{*}{ Enrolled Flagship in: Year 2} & 0.026 & 0.022 & 0.031 & 0.025 & 0.081 & 0.057 \\
\hline & $(0.020)$ & $(0.019)$ & $(0.028)$ & $(0.026)$ & $(0.043)$ & $(0.038)$ \\
\hline \multirow[t]{2}{*}{ Year 3} & 0.036 & 0.031 & 0.039 & 0.033 & 0.082 & 0.060 \\
\hline & $(0.020)$ & $(0.019)$ & $(0.027)$ & $(0.025)$ & $(0.043)$ & $(0.038)$ \\
\hline \multirow[t]{2}{*}{ Year 4} & 0.020 & 0.015 & 0.029 & 0.021 & 0.074 & 0.057 \\
\hline & $(0.019)$ & $(0.018)$ & $(0.027)$ & $(0.025)$ & $(0.043)$ & $(0.039)$ \\
\hline \multirow[t]{2}{*}{ Enrolled Priv/OOS in: Year 2} & $-0.061^{* *}$ & $-0.058^{* *}$ & -0.032 & -0.032 & -0.051 & -0.051 \\
\hline & $(0.023)$ & $(0.022)$ & $(0.032)$ & $(0.030)$ & $(0.054)$ & $(0.049)$ \\
\hline \multirow[t]{2}{*}{ Year 3} & -0.043 & -0.040 & -0.009 & -0.008 & -0.044 & -0.043 \\
\hline & $(0.023)$ & $(0.021)$ & $(0.031)$ & $(0.030)$ & $(0.051)$ & $(0.046)$ \\
\hline \multirow[t]{2}{*}{ Year 4} & -0.044 & -0.040 & -0.022 & -0.022 & -0.023 & -0.022 \\
\hline & $(0.022)$ & $(0.021)$ & $(0.031)$ & $(0.029)$ & $(0.051)$ & $(0.046)$ \\
\hline \multirow[t]{2}{*}{ Enrolled in 4-Yr: Year 2} & -0.044 & -0.040 & -0.008 & -0.012 & -0.011 & -0.029 \\
\hline & $(0.030)$ & $(0.025)$ & $(0.042)$ & $(0.035)$ & $(0.064)$ & $(0.052)$ \\
\hline \multirow[t]{2}{*}{ Year 3} & -0.023 & -0.020 & 0.024 & 0.021 & 0.030 & 0.013 \\
\hline & $(0.030)$ & $(0.026)$ & $(0.042)$ & $(0.036)$ & $(0.063)$ & $(0.051)$ \\
\hline \multirow[t]{2}{*}{ Year 4} & -0.021 & -0.017 & 0.025 & 0.019 & 0.069 & 0.050 \\
\hline & $(0.030)$ & $(0.026)$ & $(0.042)$ & $(0.036)$ & $(0.067)$ & $(0.056)$ \\
\hline \multirow[t]{2}{*}{ Transfer to More Selective School } & -0.003 & -0.001 & -0.032 & -0.029 & 0.006 & 0.007 \\
\hline & $(0.016)$ & $(0.016)$ & $(0.022)$ & $(0.022)$ & $(0.038)$ & $(0.033)$ \\
\hline \multirow[t]{2}{*}{ Transfer to Less Selective School } & 0.006 & 0.008 & 0.013 & 0.010 & -0.033 & -0.034 \\
\hline & $(0.018)$ & $(0.018)$ & $(0.026)$ & $(0.026)$ & $(0.038)$ & $(0.037)$ \\
\hline \multirow[t]{2}{*}{ Dropped Out (=0 if did not enroll) } & -0.003 & -0.002 & 0.002 & -0.001 & -0.049 & -0.057 \\
\hline & $(0.016)$ & $(0.016)$ & $(0.023)$ & $(0.023)$ & $(0.038)$ & $(0.037)$ \\
\hline \multirow[t]{2}{*}{ Total Semesters: Flagship } & 0.279 & 0.245 & 0.349 & 0.293 & $0.589^{*}$ & $0.459^{*}$ \\
\hline & $(0.150)$ & $(0.141)$ & $(0.208)$ & $(0.193)$ & $(0.261)$ & $(0.233)$ \\
\hline \multirow[t]{2}{*}{ Total Semester: 4 Year } & -0.188 & -0.161 & 0.242 & 0.202 & 0.229 & 0.130 \\
\hline & $(0.209)$ & $(0.174)$ & $(0.295)$ & $(0.240)$ & $(0.344)$ & $(0.267)$ \\
\hline \multirow[t]{2}{*}{ Total Semesters: Highly or Most Competitive } & -0.104 & -0.119 & 0.249 & 0.178 & 0.338 & 0.217 \\
\hline & $(0.196)$ & $(0.165)$ & $(0.276)$ & $(0.229)$ & $(0.320)$ & $(0.259)$ \\
\hline \multirow[t]{2}{*}{ Total Semesters: Private or Out-of-State } & $-0.396^{*}$ & $-0.376^{*}$ & -0.122 & -0.125 & -0.211 & -0.232 \\
\hline & $(0.165)$ & $(0.155)$ & $(0.227)$ & $(0.214)$ & $(0.303)$ & $(0.272)$ \\
\hline Bandwidth & 10 & 10 & 5 & 5 & IK opt bw & IK opt bw \\
\hline Baseline covariates? & No & Yes & No & Yes & No & Yes \\
\hline
\end{tabular}

precisely estimated for underrepresented minority students, but the magnitude of the estimates is similar for both groups. This pattern also holds for the other outcomes, although the negative effect on private or out-of-state enrollment is not robust to changing the bandwidth for underrepresented minority students.

Next, we examine effects stratified by whether students attend a high school with a relatively high (for the district) college-sending rate. The results strongly suggest that the effects of eligibility for automatic admission are concentrated in the higher collegesending schools. The estimated effects on flagship enrollment range from 8.5 percentage 


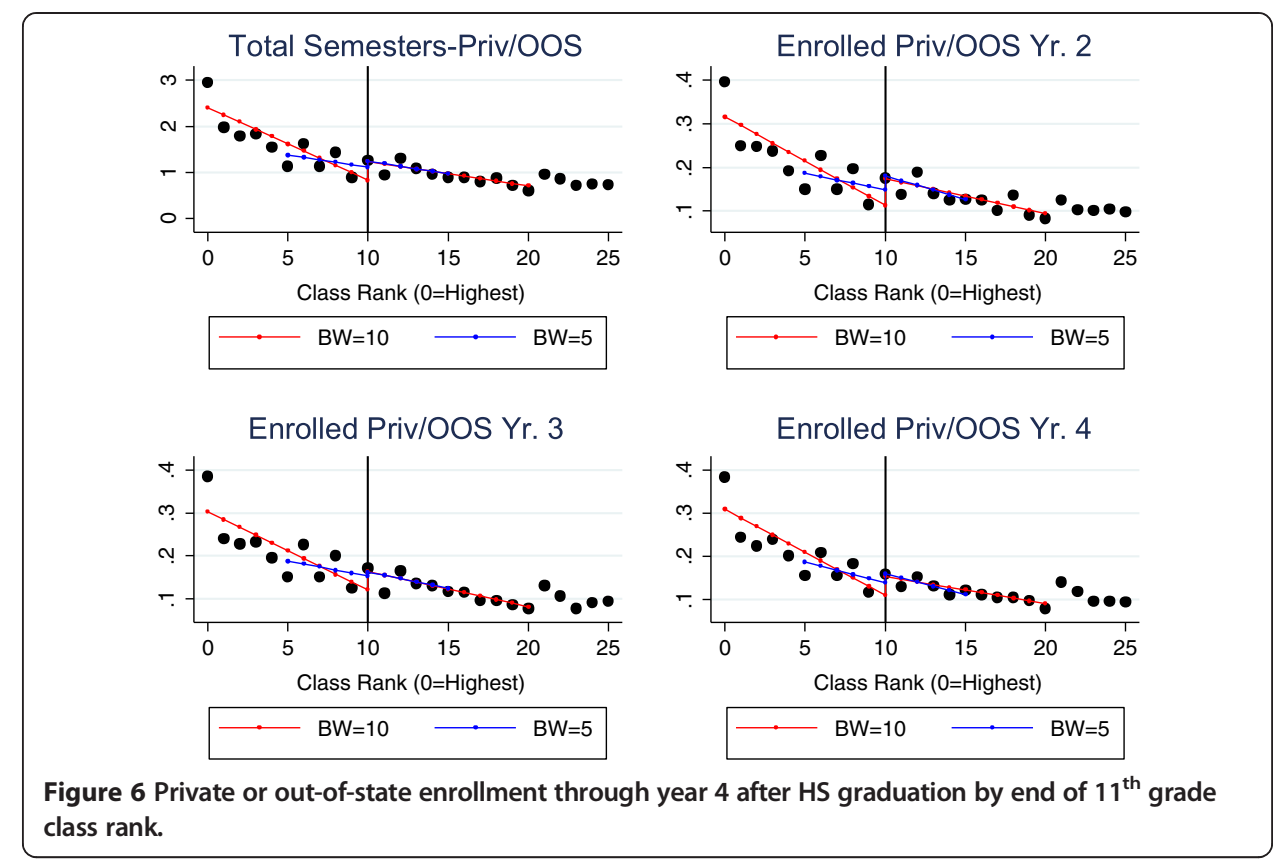

points to 15.7 percentage points in the IK specification. The estimates for the total semesters of flagship enrollment are only statistically significant when the bandwidth is 10, but the point estimates are similar in magnitude for the other specifications. In contrast, we do not find any evidence of impacts on flagship enrollment for students from low college-sending high schools, and the estimated effects on total semesters in a flagship are not statistically significant and change signs across specifications. Despite the lack of effects on flagship enrollment, we find negative effects on private or out-of-state enrollment and total semesters in a four-year college. However, these estimates are only statistically significant with a bandwidth of 10 and are much

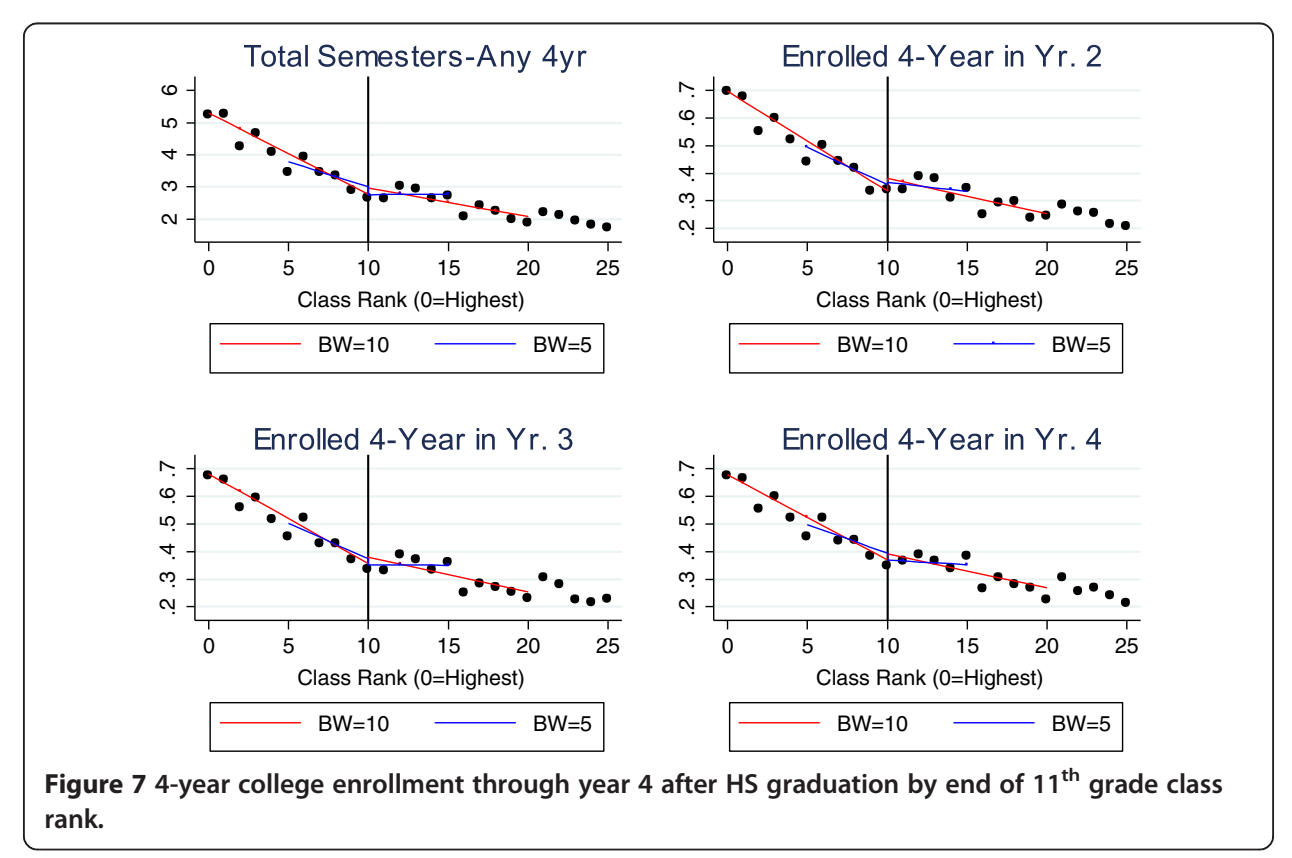




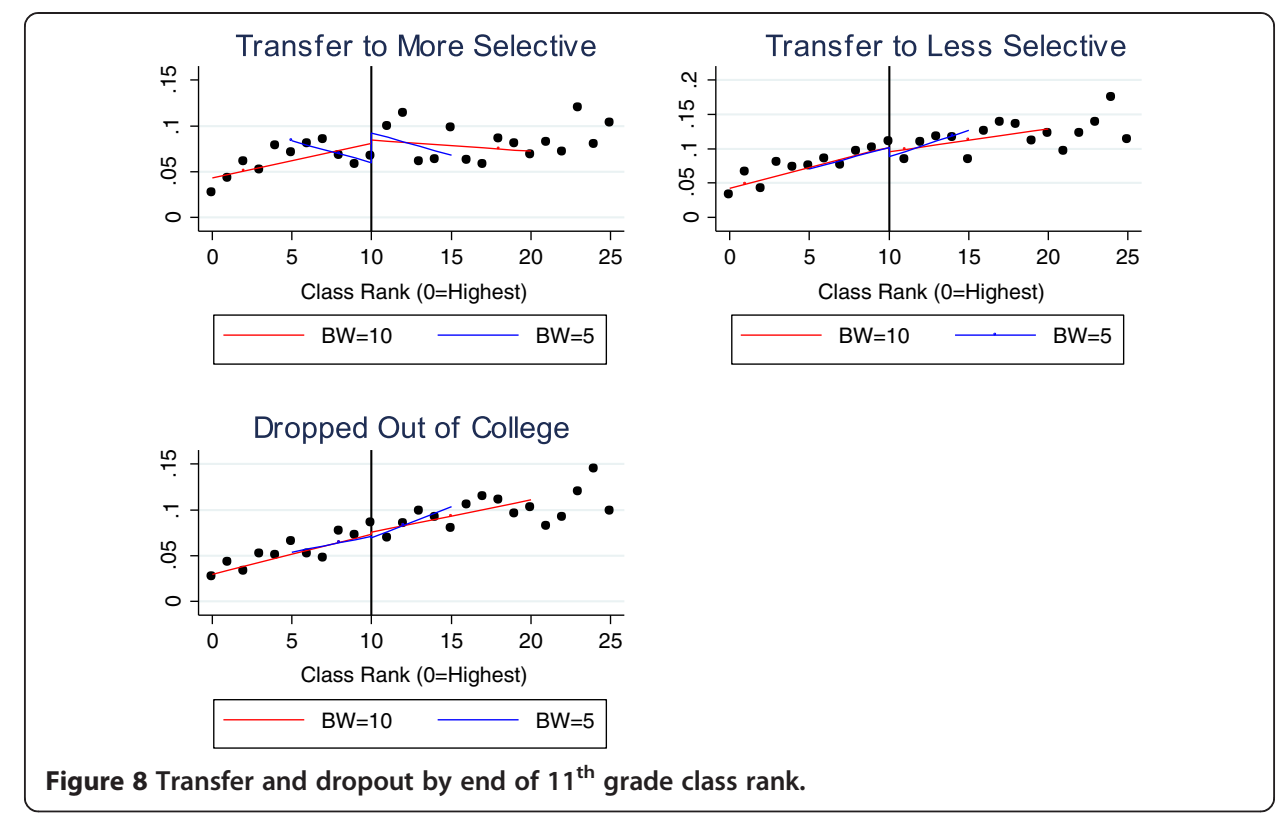

smaller in magnitude and not statistically significant in the other two specifications. When interpreting these results, it is important to remember that even the higher college-sending high schools in the district have relatively low college-sending rates relative to the state as a whole. Nonetheless, these results indicate that eligibility for automatic admissions may have little effect on college enrollment and choice for the most disadvantaged urban high schools.

The third panel shows results by socioeconomic status. The estimated effects on flagship enrollment are larger in magnitude for students who are not economically disadvantaged and range from 9-13 percentage points. In contrast, they are only statistically significant for the economically disadvantaged sample in the IK specification. The estimates for total semesters of flagship enrollment also are larger for the not economically disadvantaged sample, and the estimates for the economically disadvantaged sample are small in magnitude and statistically insignificant. For both groups, we find negative and statistically significant effects on private or out-of-state enrollment in the bandwidth of 10 specification, and for the non-economically disadvantaged sample the estimate for the IK specification is even larger in magnitude (although not statistically significant).

Finally, we examined results by gender. The estimated effects on flagship enrollment are larger for women than they are for men. However, the difference in magnitudes is not especially large, and the estimated effects on total semesters on flagship enrollment are larger for men in some specifications than for women. Overall, these results do not offer clear evidence of differential effects by gender.

\section{Discussion and conclusion}

Attending a selective college is widely seen as providing students, particularly those from disadvantaged backgrounds, access to opportunities that are otherwise difficult to obtain. Consistent with this view, evidence from recent studies suggests that selective college attendance has sizable returns that are especially large for lower-income and minority students. Nonetheless, there remain large gaps in selective college attendance 
Table 5 Effects of being in top $10 \%$ at end of 11 th grade by subgroups

\begin{tabular}{|c|c|c|c|c|c|c|}
\hline \multirow{2}{*}{$\begin{array}{l}\text { Race } \\
\text { Enrolled in Flagship }\end{array}$} & \multicolumn{3}{|c|}{ Whites \& Asians } & \multicolumn{3}{|c|}{ Under-represented minorities } \\
\hline & 0.054 & 0.048 & 0.113 & $0.053^{* *}$ & $0.085^{* *}$ & $0.075^{* *}$ \\
\hline & $(0.037)$ & $(0.054)$ & $(0.084)$ & $(0.020)$ & $(0.025)$ & $(0.027)$ \\
\hline \multirow[t]{2}{*}{ Enrolled Private or Out-of-State } & $-0.083^{*}$ & -0.045 & -0.135 & $-0.076^{* *}$ & -0.010 & 0.001 \\
\hline & $(0.038)$ & $(0.054)$ & $(0.094)$ & $(0.027)$ & $(0.038)$ & $(0.059)$ \\
\hline \multirow[t]{2}{*}{ Total Semesters: Flagship } & 0.255 & 0.209 & 0.560 & $0.260^{*}$ & $0.429^{* *}$ & $0.371^{*}$ \\
\hline & $(0.269)$ & $(0.393)$ & $(0.439)$ & $(0.129)$ & $(0.166)$ & $(0.156)$ \\
\hline \multirow[t]{2}{*}{ Total Semester: 4 Year } & -0.138 & 0.157 & 0.256 & -0.209 & 0.367 & 0.119 \\
\hline & $(0.283)$ & $(0.414)$ & $(0.458)$ & $(0.219)$ & $(0.286)$ & $(0.319)$ \\
\hline HS College-Sending Level & \multicolumn{3}{|c|}{ High college sending } & \multicolumn{3}{|c|}{ Low college sending } \\
\hline \multirow[t]{2}{*}{ Enrolled in Flagship } & $0.085^{* *}$ & $0.095^{*}$ & $0.157^{*}$ & -0.004 & 0.013 & -0.002 \\
\hline & $(0.030)$ & $(0.042)$ & $(0.062)$ & $(0.019)$ & $(0.025)$ & $(0.025)$ \\
\hline \multirow[t]{2}{*}{ Enrolled Private or Out-of-State } & $-0.065^{*}$ & -0.039 & -0.091 & $-0.099^{* *}$ & -0.022 & -0.039 \\
\hline & $(0.032)$ & $(0.045)$ & $(0.071)$ & $(0.028)$ & $(0.041)$ & $(0.057)$ \\
\hline \multirow[t]{2}{*}{ Total Semesters: Flagship } & $0.423^{*}$ & 0.428 & 0.589 & -0.070 & 0.047 & 0.118 \\
\hline & $(0.216)$ & $(0.303)$ & $(0.339)$ & $(0.118)$ & $(0.132)$ & $(0.107)$ \\
\hline \multirow[t]{2}{*}{ Total Semester: 4 Year } & 0.058 & 0.402 & 0.384 & $-0.503^{*}$ & -0.085 & -0.222 \\
\hline & $(0.242)$ & $(0.344)$ & $(0.376)$ & $(0.230)$ & $(0.300)$ & $(0.359)$ \\
\hline SES & \multicolumn{3}{|c|}{ Not econ. Disadvantaged } & \multicolumn{3}{|c|}{ Economically disadvantaged } \\
\hline \multirow[t]{2}{*}{ Enrolled in Flagship } & $0.089^{* *}$ & $0.097^{*}$ & 0.128 & 0.006 & 0.025 & $0.056^{*}$ \\
\hline & $(0.032)$ & $(0.046)$ & $(0.065)$ & $(0.020)$ & $(0.024)$ & $(0.028)$ \\
\hline \multirow[t]{2}{*}{ Enrolled Private or Out-of-State } & $-0.075^{*}$ & -0.031 & -0.101 & $-0.076^{* *}$ & -0.026 & -0.015 \\
\hline & $(0.035)$ & $(0.048)$ & $(0.079)$ & $(0.028)$ & $(0.040)$ & $(0.053)$ \\
\hline \multirow[t]{2}{*}{ Total Semesters: Flagship } & $0.472^{*}$ & 0.428 & 0.584 & -0.041 & 0.139 & 0.111 \\
\hline & $(0.233)$ & $(0.329)$ & $(0.374)$ & $(0.127)$ & $(0.144)$ & $(0.138)$ \\
\hline \multirow[t]{2}{*}{ Total Semester: 4 Year } & -0.004 & 0.266 & 0.127 & -0.342 & 0.195 & 0.014 \\
\hline & $(0.256)$ & $(0.363)$ & $(0.400)$ & $(0.233)$ & $(0.307)$ & $(0.323)$ \\
\hline Gender & & Women & & & Men & \\
\hline \multirow[t]{2}{*}{ Enrolled in Flagship } & $0.061^{* *}$ & $0.083^{* *}$ & $0.127^{* *}$ & 0.042 & 0.038 & 0.107 \\
\hline & $(0.023)$ & $(0.031)$ & $(0.044)$ & $(0.038)$ & $(0.055)$ & $(0.073)$ \\
\hline \multirow[t]{2}{*}{ Enrolled Private or Out-of-State } & $-0.094^{* *}$ & -0.029 & -0.085 & -0.056 & -0.028 & -0.163 \\
\hline & $(0.027)$ & $(0.038)$ & $(0.056)$ & $(0.040)$ & $(0.057)$ & $(0.091)$ \\
\hline \multirow[t]{2}{*}{ Total Semesters: Flagship } & 0.191 & 0.287 & $0.595^{*}$ & 0.393 & 0.363 & 0.458 \\
\hline & $(0.161)$ & $(0.217)$ & $(0.260)$ & $(0.271)$ & $(0.389)$ & $(0.386)$ \\
\hline \multirow[t]{2}{*}{ Total Semester: 4 Year } & -0.303 & 0.046 & -0.027 & 0.086 & 0.559 & 0.491 \\
\hline & $(0.215)$ & $(0.294)$ & $(0.325)$ & $(0.299)$ & $(0.439)$ & $(0.460)$ \\
\hline Bandwidth & 10 & 5 & IK opt bw & 10 & 5 & IK opt bw \\
\hline
\end{tabular}

Note: See notes to Tables 4 and 5. All estimates are from models that include controls for baseline covariates. Robust standard errors in parentheses. ${ }^{*},{ }^{*}$ denote statistically significant estimate at the $1 \%$ and $5 \%$ level, respectively.

and completion by race and socioeconomic status. Policies to address these gaps are therefore an important social and economic issue.

The Texas Top Ten Percent Plan is an example of such a policy. In this paper, we estimated the effects of eligibility for the automatic admissions guarantee this policy provides to students in the top decile of their high school class. We did so using administrative data from a large urban school district in Texas linked to college 
enrollment records and a regression discontinuity approach that compared the outcomes of students who just made the cutoff for the TTP and those who just missed it.

The analysis discussed in this paper generated several notable findings that have important policy implications. First, our results demonstrate that eligibility for automatic admissions does appear to increase enrollment at flagship universities for students in an urban school district that sends relatively few students to college who are at the margin of being in the top decile of their class. In particular, we also find these effects for underrepresented minority students. These findings are noteworthy because a key goal of the TTP Plan, and percent plans in general, is to increase access to the top public universities for traditionally under-served populations.

Despite these effects on flagship enrollment, we find little evidence that the automatic admissions guarantee leads to increases in the "quality" of the colleges students attend. Instead, the increases in flagship enrollment appear to "crowd out" enrollment at comparably ranked private or out-of-state institutions. Thus, offering eligibility for automatic admissions does not appear to increase access to selective colleges in general even if it increases access to the best public universities in Texas.

We also find that the effects on flagship enrollment are concentrated in the most advantaged schools in the district. Indeed, when we estimated effects by the fraction of students at a high school that attend college, we found no evidence of effects on college choice in the schools with the lowest college-sending rates. While the college-sending rates of the highest performing high schools are not very high relative to Texas as a whole, our findings suggest that offering eligibility for automatic admissions may not be effective at accomplishing even the narrow goal of increasing access to the top public universities for students in the most disadvantaged settings.

These results complement other research showing that ending affirmative action decreased enrollment of underrepresented minority students at selective colleges and descriptive analyses showing that percent plans do not fully offset these reductions. While we do not examine the effect of introducing the TTP Plan, we find little evidence that the centerpiece of this policy - the automatic admissions guarantee - increases enrollment at competitive universities or that it increases access to public flagship universities for students at the most disadvantaged schools. These results are consistent with the claim that percent plans are unlikely to have large aggregate impacts on selective college enrollment among students from backgrounds that send relatively few students to these schools.

There are also some important questions that our paper does not address. Since we use data from an urban school district, our findings may not reflect how automatic admissions guarantees affect students in rural or suburban schools. While the effects on students in urban school districts have clear importance for policy, the effects in other settings do as well. The effects in rural areas are important because a goal of the TTP Plan is to increase geographic diversity at the state's public universities. Likewise, the effects in suburban areas have significance because many of the criticisms about the policy's fairness stem from concerns that students in suburban districts are at a disadvantage because it is harder to get into the top decile. Nonetheless, it is plausible that the lack of effects on college selectivity that we find may hold in higher-income districts as well since students in these districts who are at the margin for being in the top decile of their class likely face smaller 
informational and financial barriers to enrolling in high-quality colleges than do students in our sample.

The generalizability of our findings is also limited by the regression discontinuity research design that we use, which implies that our results only pertain to students at the margin for eligibility for automatic admission. Nonetheless, the effect for the marginal student is important for policy. For instance, these effects are relevant for thinking about the effects of changing the class rank cutoff for eligibility for automatic admissions. Furthermore, the effects of the automatic admissions guarantee might be largest for marginal students since they are likely to be weaker than other students in the top class rank decile on other dimensions used in college admissions decisions.

Finally, our results cannot speak to the overall effects of instituting the TTP Plan. These effects might include strategic behavior such as choosing less competitive high schools to make it easier to get the admissions guarantee (Cullen et al. 2013) as well as changes in student effort and course-taking behavior. Determining whether these and other unintended consequences of percent plans exist is an important area for future research.

\section{Endnotes}

${ }^{1}$ There are also gaps in enrollment and completion of any type college by race and socioeconomic status (Bailey and Dynarski, 2012), but the gaps are more pronounced for selective colleges (Carnevale and Rose, 2004).

${ }^{2}$ Other examples of policies that are designed in part to increase selective college enrollment among lower-income and minority students include offering incentives to take Advance Placement coursework (Jackson, 2010a; 2010b), mandatory college entrance exam testing (Goodman, 2012) and expanding entrance exam testing centers (Bulman, George 2012), and interventions that provide individualized information on college choices and the net cost of college attendance (Avery 2010; Bettinger et al. 2012; Hoxby and Avery 2012).

${ }^{3}$ Percent plans have also been criticized because students with weaker academic backgrounds from less competitive high schools might be "overmatched" at a selective college and do worse than they would at a less selective institution (Sander, 2004; Sander and Taylor, 2012). On the other hand, students with stronger academic records could be "undermatched" when attending a less-selective college (Bowen et al. 2009). Fletcher and Mayer (2013) find no evidence of mismatch effects of students admitted under the TTP Plan.

${ }^{4}$ During our study period, there were no restrictions on the number of students admitted and who could enroll under TTP. In 2009, legislation was passed limiting the number of top ten percent admissions to the University of Texas - Austin. The policy went into effect for the 2011 entering class at UT.

${ }^{5}$ Cohodes and Goodman (forthcoming) find that a scholarship program in Massachusetts led to a shifting of students into lower-quality public universities from higher-quality private universities. In contrast, the public flagship universities in Texas are more selective than those in Massachusetts.

${ }^{6}$ A 1996 decision by the U.S. $5^{\text {th }}$ Circuit Court in Hopwood v. Texas banned the use of race in college admissions. The 2003 Supreme Court ruling in Grutter v. Bollinger upheld a policy of using racial affirmative action. After the decision, the University of 
Texas reinstated racial preferences in admissions. In 2013, Fisher v. University of Texas is the most recent challenge to racial affirmative action. The Supreme Court did not rule on the constitutionality of racial preferences. Instead, it remanded the issue to the lower $5^{\text {th }}$ Circuit Court, allowing Grutter to stand. There have also been political challenges to affirmative action. For instance, voters in California, Arizona, and Michigan have passed ballot measures that ban affirmative action.

${ }^{7}$ Both UT and TAMU offer scholarships targeted to students at schools that traditionally do not send students to flagships. For UT Longhorn Opportunity Scholarship, students need not be in the top ten percent to qualify, but this is a requirement of the TAMU Century Scholarship program. Very few students obtain and use these scholarships. For example, in 2005, only 13 students from the school district we study were awarded the Longhorn Opportunity Scholarship and enrolled in UT.

${ }^{8}$ Institutional policies such as UT's Coordinated Admissions Program and articulation agreements with community colleges provide opportunities for students attending other colleges to transfer to flagship universities.

${ }^{9}$ In contrast, other districts allow individual schools to calculate class rank, potentially using different algorithms to determine absolute class rank and the denominator for calculating percentile rank. In fact, our study district recently decentralized class rank calculations, and now the individual high schools calculate class rank themselves.

${ }^{10}$ In the district, class rank is based on weighted GPA, with regular courses receiving a weight of 4 for an "A" and advanced-courses receiving a weight of 5 for an "A". Grades from "local credit only" courses and courses from which students withdrew are not included in the GPA calculations.

${ }^{11}$ UT-Austin and Texas A\&M are ranked as "highly competitive" along with 7 other colleges in Texas (of these, only UT-Dallas is a public university). Rice University is the only university in Texas ranked as "most competitive".

${ }^{12}$ This prediction holds in our sample. For students in the top quintile of the $11^{\text {th }}$ grade percentile class rank distribution (the sample used in the RD analysis; see below for further details), percentile class rank between end of $11^{\text {th }}$ grade and graduation increases by about 2.6 percentage points (meaning that students' relative ranking worsens since the student ranked number 1 in the class has a percentile class rank of 1 divided by the class size), and 82 percent of students experience a worsening in percentile class rank. In contrast, mean GPA growth over this period is essentially zero. Moreover, 20 percent of students in the top ten percent of their class at the end of $11^{\text {th }}$ grade are not in the top ten percent of their class at graduation (only 2 percent who were not in the top ten percent at the end of $11^{\text {th }}$ grade are in the top ten percent at graduation).

${ }^{13}$ Indeed, when we use class rank at graduation as the running variable in the RD analysis, we do not find any evidence of effects of top ten percent status on college choice. Notably, most of the estimates of the effect on flagship enrollment are negative (meaning that being in the top ten percent reduces flagship enrollment), although statistically insignificant.

${ }^{14}$ The other main way the research design could be undermined is if school officials manipulate the calculation of class rank to increase the number of its students eligible for automatic admissions via the TTP Plan. However, as described above, during our study period class rank was calculated at the district central office using an automated 
procedure, so we do not think this type of gaming was empirically important during the time covered by our analysis.

${ }^{15}$ Because the range of percentile class rank values above the $90^{\text {th }}$ percentile cutoff is relatively small, we do not report results from "global polynomial" models that use the complete range of class rank and control for a polynomial in class rank.

${ }^{16}$ There may be other benefits to being in the TTP not related to the Texas TTP Plan. For instance, some scholarships may be offered to students if they are in the TTP of their class. During our study period Texas had no such statewide policy, and we do not know of any examples at the main schools attended by students in our sample. Nonetheless, if there are such effects, then our estimates capture the "reduced form" effect of the TTP policy provisions and any other benefits of being in the TTP.

${ }^{17}$ Two recent papers (Pei, 2011; Hullegie and Klein, 2010) propose methods to account for measurement error in the running variable in RD designs. Unfortunately we cannot use these in our application because they require actual treatment status (in our case, TTP status) to be observed. The measure of TTP status used in the analysis is based on the observed (potentially noisy) class rank measure.

${ }^{18}$ Students who did not enroll in college are assigned a value of 1 for the probability of being admitted. We obtain similar results if limiting the sample to students who enroll in colleges with non-missing data on the fraction of applicants admitted.

${ }^{19}$ Students who did not attend college and who therefore have no tuition are assigned a tuition value of zero. The rationale for this decision is that not attending college has a cost of zero. We obtain similar results when restricting the sample to students who have non-missing tuition data.

${ }^{20}$ Such an effect could be consistent with the claim made by some that underqualified students admitted via preferential treatment (in this case automatic admission by virtue of the TTP Plan) might be "overmatched" to an institution that is too demanding and that they would have worse outcomes than they would have had they enrolled in a less demanding institution (see Arcidiacono et al., 2011; Hinrichs, 2012; and Rothstein and Yoon, 2008 for a discussion and evidence on the "mismatch hypothesis"). However we do not interpret our findings as evidence on the "mismatch hypothesis" because we do not find evidence that TTP status affects the selectivity of the colleges students attend.

Competing interests

The IZA Journal of Labor Economics is committed to the IZA Guiding Principles Reserach Integrity. The authors declare that they have observed these principles.

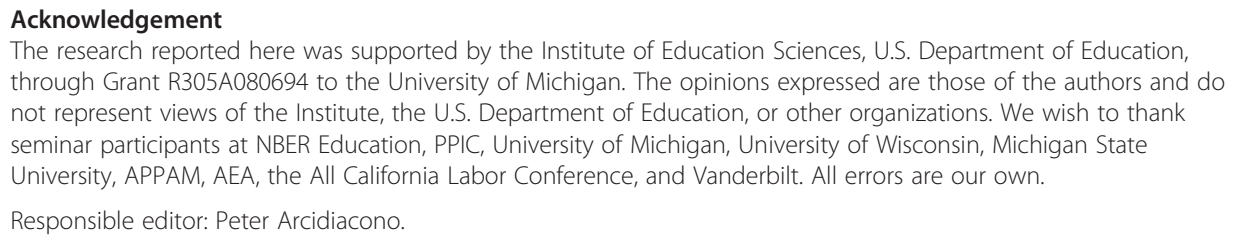


References

Andrews RJ, Li J, Lovenheim M (2012) Quantile treatment effects of college quality on earnings: evidence from administrative data in Texas. NBER Working Paper No. 18068.

Antonovics K, B B (2013) Were minority students discouraged from applying to university of California campuses after the affirmative action Ban? Education, Finance and Policy Spring 8(2):208-50

Arcidiacono P, Aucejo E, Fang H, Spenner K (2011) Does affirmative action lead to mismatch? a new test and evidence. Quant Econ 2(2011):303-333

Avery, C (2010) The effects of college counseling on high-achieving, low-income students. NBER Working Paper No. 16359.

Bailey M, Dynarski S (2012) Gaps: changing inequality in U.S. college entry and completion. In: Duncan G, Murnane R (eds) Wither opportunity? rising inequality, schools, and children's life chances. Russell Sage Foundation.

Barr R (2005) Should Texas change the top 10 percent law? Focus Report, House Research Organization

Bastedo M, Jaquette $O$ (2011) Running in place: low-income students and the dynamics of higher education stratification. Educational Evaluation and Policy Analysis 33(3):318-339

Bettinger E, Long B, Oreopoulos P, Sanbonmatsu L (2012) The role of application assistance and information in college decisions: results from the H\&R block FAFSA experiment. Q J Econ 127(3):1205-1242

Bowen WG, Bok D (1998) The shape of the river: long-term consequences of considering race in college and university admissions. Princeton University Press.

Bowen WG, Chingos M, McPherson M (2009) Crossing the finish line: completing college at America's public universities. Princeton University Press.

Brown SK, Hirschman C (2006) The end of affirmative action in Washington State and its impact on the transition from high school to college. Sociol Educ 79:106-130

Bulman, George (2012) The effect of access to college assessments on enrollment and attainment. Stanford University manuscript, https://bepp.wharton.upenn.edu/bepp/assets/File/AE-S13-Bulman.pdf.

Card D, Krueger A (2005) Would the elimination of affirmative action affect highly qualified minority applicants? evidence from California and Texas. Ind Labor Relat Rev 58(3):416-434

Carnevale A, Rose S (2004) Socioeconomic status, race/ethnicity, and selective college admissions. In: Richard K (ed) America's untapped resource. Twentieth Century Fund.

Cohodes S, Goodman J (forthcoming) Merit aid, college quality and college completion: Massachusetts' Adams scholarship as an in-kind subsidy. Am Econ J Appl Econ, forthcoming

Cullen J, Long M, Reback R (2013) Jockeying for position: strategic high school choice under Texas' top ten percent plan. Journal of Public Economics.

Dale S, Krueger A (2002) Estimating the payoff to attending a more selective college: an application of selection on observables and unobservables. Q J Econ 117(4):1491-1527

Dale S, Krueger A (2011) Estimating the return to college selectivity over the career using administrative earnings data. NBER Working Paper No. 17159.

Fletcher J, Mayer A (2013) Tracing the effects of guaranteed admission through the college process: evidence from a policy discontinuity in the Texas 10\% plan. Policy, Contemporary Economic

Goldin C, Katz L (2008) The race between education and technology. Harvard University Press.

Goodman S (2012) Learning from the test: raising selective college enrollment by providing information. Columbia University mimeograph.

Hinrichs P (2010) The effects of affirmative action bans on college enrollment, educational attainment, and demographic composition of universities. Rev Econ Stat 94(3):712-722

Hinrichs P (2012) Affirmative action bans and college graduation rates. Unpublished Manuscript

Hoekstra M (2009) The effect of attending the flagship state university on earnings. Review of Economics \& Statistics 91(4):717-724

Holzer HJ, Neumark D (2000) What does affirmative action do? Ind Labor Relat Rev 53(2):240-271

Horn CL, Flores SM (2003) Percent plan in college admissions: a comparative analysis of three States' experiences. The Civil Rights Project at Harvard University, Cambridge, MA

Hoxby C (2001) The return to attending a more selective college: 1960 to present. Exploring the Future of Higher Education, Editors Maureen Devlin and Joel Meyerson, In Forum Futures

Hoxby CM, Avery C (2012) The missing 'One-offs": the hidden supply of high-achieving, low income students. NBER Working Paper No. 18586.

Hullegie P, Klein T (2010) The effect of private health insurance on medical care utilization and self-assessed health in Germany. Health, Economics

Imbens G, Kalyanaraman K (2009) Optimal bandwidth choice for the regression discontinuity estimator. NBER Working Paper No. 14726.

Imbens G, Lemieux T (2008) Regression discontinuity designs: a guide to practice. J Econ 142(2):615-635

Jackson CK (2010a) A little now for a lot later: a look at a Texas advanced placement incentive program. J Hum Resour 45(3):591-639

Jackson CK (2010b) The effects of an incentive-based high-school intervention on college outcomes. NBER Working Paper No. 15722.

Jacob B, McCall B, Stange K (2013) College as country club: do colleges cater to Students' preferences for consumption? NBER Working Paper No. 18745.

Juhn C, Murphy K, Pierce B (1993) Wage inequality and the rise in the return to skills. J Polit Econ 101(3):410-442

Katz LF, Murphy KM (1992) Changes in relative wages, 1963-1987: supply and demand factors. Q J Econ 107(1):35-78

Lee D (2008) Randomized experiments from non-random selection in U.S. house elections. J Econ 142(2):675-697

Long BT (2004a) How have college decisions changed over time? an application of the conditional logistic choice model. J Econ 121(1-2):271-296

Long M (2004b) Race and college admissions: an alternative to affirmative action? Review of Economics and Statistics 86(4):1020-1033

Long M, Tienda M (2008) Winners and losers: changes in Texas university admissions post Hopwood. Educational Evaluation and Policy Analysis 30(3):255-280 
Long M, Saenz V, Tienda M (2010) Policy transparency and college enrollment: did the Texas top ten percent Law broaden access to the public flagships? The Annals of the American Academy of Political and Social Science 627(January):82-105

Marin P, Lee EK (2003) Appearance and reality in the sunshine state: the talented 20 program in Florida. The Civil Rights Project at Harvard University, Cambridge, MA

McCrary J (2008) Manipulation of the running variable in the regression discontinuity design: a density test. J Econ 142(2):698-714, http://dx.doi.org/10.1016/j.jeconom.2007.05.005

Niu S, Tienda M (2010) The impact of the Texas top 10 percent law on college enrollment: a regression discontinuity approach. Journal of Policy Analysis and Management 29(1):84-110

Niu S, Sullivan T, Tienda M (2006a) Diversity by design or default? minority students and the Texas top 10\% law. Paper presented at the annual meeting of the population association of America, Los Angeles, CA

Niu S, Tienda M, Cortes KE (2006b) College selectivity and the Texas top 10\% law: how constrained are the options? Econ Educ Rev 25(3):259-272

Owings J, McMillen M, Burkett J, Daniel B (1995) Making the cut: who meets highly selective college entrance criteria? statistics in brief. National Center for Education Statistics. http://nces.ed.gov/pubs95/95732.pdf

Pallais A, Turner S (2006) Access to elites: the growth of programs to increase opportunities for low-income students at selective universities. In: Dickert-Conlin S, Rubenstein R (eds) Economic inequality and higher education: access, persistence, and success. Russell Sage Foundation, New York

Pei Z (2011) "Regression discontinuity design with measurement error in the assignment variable", mimeograph. Princeton University.

Reardon SF, Baker R, Klasik D (2012) Race, income, and enrollment patterns in highly selective colleges, 1982-2004. Stanford University Center for Education Policy Analysis Working Paper, http://cepa.stanford.edu/content/raceincome-and-enrollment-patterns-highly-selective-colleges-1982-2004\#sthash.N4t0G38Z.dpuf

Rothstein J, Yoon A (2008) Mismatch in law school. NBER Working Paper No. 14275, http://www.nber.org/papers/ W14275

Sander RH (2004) A systemic analysis of affirmative action in American law schools. Stanford Law Review 57(2):367-483

Sander RH, Taylor S (2012) Mismatch: how affirmative action hurts students It's intended to help, and why universities won't admit it. Basic Books, New York City, New York

THECB (2010) Texas high school graduates - college enrollment trends 2003-2009. http://www.thecb.state.tx.us/reports/ PDF/2455.PDF?CFID $=29991746 \&$ CFTOKEN $=22384481$

Tienda M, Alon S, Niu SX (2008) Affirmative action and the Texas top 10\% percent admission law: balancing equity and access to higher education. Sociétés Contemporaines 79:5-96

U.S. Department of Education (2003) Race-neutral alternatives in postsecondary education: innovative approaches to diversity. http://www2.ed.gov/about/offices/list/ocr/edlite-raceneutralreport.html

Walker B, Lavergne G (2001) Affirmative action and percent plans: what we learned in Texas. The College Board Review 193:18-23

Winston GC, Hill CB (2005) Access to the most selective private colleges by high-ability, low-income students: are they out there? Working Paper, Williams College Project on Higher Education.

Zimmerman S (2014) The returns to College Admission for Academically marginal students. J Labor Econ 32(4):711-754

10.1186/2193-8997-3-10

Cite this article as: Daugherty et al:: Percent plans, automatic admissions, and college outcomes. IZA Journal of Labor Economics 2014, 3:10

\section{Submit your manuscript to a SpringerOpen ${ }^{\circ}$ journal and benefit from:}

- Convenient online submission

- Rigorous peer review

- Immediate publication on acceptance

- Open access: articles freely available online

- High visibility within the field

Retaining the copyright to your article

Submit your next manuscript at $\gg$ springeropen.com 